\title{
max \\ Quality Improvement and Cost Evaluation of Pellet Fuel Produced from Pruned Fruit Tree Branches
}

\author{
Yining $\mathrm{Li}^{1,2}$, Kang Kang ${ }^{3,4, *}$ and Wei Wang ${ }^{2,5}$ \\ 1 School of Mechanical Engineering, Shaanxi Polytechnic Institute, Xianyang 712000, China; \\ liyining@sxpi.edu.cn \\ 2 Xianyang Key Laboratory of New Power and Intelligent Microgrid System, Xianyang 712000, China; \\ wangwei05@sxpi.edu.cn \\ 3 Institute for Chemicals and Fuels from Alternative Resources (ICFAR), Western University, \\ London, ON NOM 2A0, Canada \\ 4 College of Mechanical and Electronic Engineering, Northwest A\&F University, Xianyang 712100, China \\ 5 School of Aeronautical Engineering, Shaanxi Polytechnic Institute, Xianyang 712000, China \\ * Correspondence: kknwafu@hotmail.com
}

check for updates

Citation: Li, Y.; Kang, K.; Wang, W. Quality Improvement and Cost Evaluation of Pellet Fuel Produced from Pruned Fruit Tree Branches. Energies 2022, 15, 113. https:// doi.org/10.3390/en15010113 Academic Editors: Idiano D'Adamo and Piergiuseppe Morone

Received: 15 November 2021 Accepted: 23 December 2021 Published: 24 December 2021

Publisher's Note: MDPI stays neutral with regard to jurisdictional claims in published maps and institutional affiliations.

Copyright: (C) 2021 by the authors. Licensee MDPI, Basel, Switzerland. This article is an open access article distributed under the terms and conditions of the Creative Commons Attribution (CC BY) license (https:/ / creativecommons.org/licenses/by/ $4.0 /)$.

\begin{abstract}
Biomass-based pellet is an important source of renewable energy. In this study, to obtain the high-quality fuel pellet via the densification of pruned branches of fruit trees, we investigated the optimization of blending ratios for different raw materials using branches from jujube (Ziziphus jujuba Mill.), which is a widely distributed waste biomass resource in China. Through the characterization of raw materials and pellets, the effects of different raw materials on the storage, transportation, and combustion performances of the pellets can be understood. The cost evaluation analysis showed that the two optimized, co-densified pellets had great cost advantages compared with the pure jujube branch pellets. This indicates the potential industrial value of optimized pellets. The results of this study can help to improve the application value of orchard residues and generate an additional profit for fruit plantations, simultaneously avoiding the environmental damage caused by its open combustion.
\end{abstract}

Keywords: orchard residues; densification; formula parameters; biomass; bioenergy

\section{Introduction}

Energy has always been crucial for human survival and development [1]. In recent years, the fast consumption of fossil energy has shown an increasingly negative impact on the global environment [2,3]. Hence, the development and utilization of alternative energy sources have become major concerns at the global scale [4,5]. In response to this, biomass energy received an increasing amount of attention as an environmentally friendly energy source $[6,7]$.

Every type of organic matter produced directly or indirectly from the process of photosynthesis is considered biomass [8]. Orchard residues are an important type of biomass that is abundant, widely distributed, and renewable [9]. China is a major fruit-producing and exporting country, with a fruit cultivation area that reached $12,276,700 \mathrm{hm}^{2}$ by the end of 2019. The pruned branches of fruit trees produced during routine orchard management are one of the key producers of Chinese orchard residues [10,11]. However, due to their low bulk density and complicated geological distribution, pruned branches are often treated as solid waste. Additionally, their poor storage, transportation, and combustion performance makes economic benefits difficult, further resulting in excessive resource waste and environmental pollution through open combustion $[12,13]$.

For this reason, the pruned branches of fruit trees and other orchard residues can be densified into pellets, and used for industrial power generation or home heating [14,15]. Compared to forestry residues, pruned branches of fruit trees have a higher ash content and lower energy density, so they are not a conventionally desirable raw material for 
producing pellets. Therefore, they can be blended with forestry residues such as pine wood, with the advantages of both combined [16]. However, this approach raises new issues. Specifically, the pruned branches of fruit trees and forestry residues, which can complement each other, are not always produced at the same geological location. Due to the far distance of the production source, the cost of biomass resources will increase dramatically with the increase in the transportation distance. Therefore, they are more suitable for local acquisition, processing, sales, and use. Hence, to improve pellet quality at an acceptable cost, it is necessary to consider other biomass fuels from the same origin as the pruned branches of fruit trees for co-densification. For example, by co-densifying the pruned branches and pomace of olive trees, the mechanical strength and bulk density of pellets can be significantly improved [17]. Another effective approach is to increase the fixed carbon content and higher heating value of biomass feedstock by further thermochemical processing, such as conversion into biochar [14]. However, biochar has a lower mechanical strength and often requires additives for binding during densification [18].

In order to solve the above problems, in this study, pruned branches of fruit trees and their biochar were mixed and co-densified in proportion, and an appropriate amount of biomass additives were used to obtain pellets with an excellent quality and controllable cost without increasing process complexity.

\section{Materials and Methods}

\subsection{Raw Materials}

The raw materials used for pellet production were categorized as main raw materials, secondary raw materials, and additives [19]. The jujube tree (Ziziphus jujuba Mill.) is native to China and often grows below $1700 \mathrm{~m}$ sea level in various landforms, mountains, hills, or plains. Currently, the jujube tree is widely planted in 21 provincial-level administrative regions (34 in total) in China and is one of the most distinctive local fruits in the country. China's jujube planting area covers about $3,250,000 \mathrm{hm}^{2}$, accounting for $26.47 \%$ of the country's total fruit tree planting area. Therefore, the use of pruned jujube tree branches (JB) as a primary feedstock, and their charcoals (JBC) as a secondary feedstock, to produce pellet could significantly reduce the quantity of the waste jujube biomass by converting it into clean fuel. In addition, considering the cost and potential pollution problems, it is best to use biomass-based raw materials, which are low-cost and available in large quantities, as additives. A preliminary experiment showed that coco coir (CC) and bone meal (BM) in garden flower fertilizer had better properties as additives. CC and BM meet the requirements for additives in the recommended standard of the Ministry of Agriculture of China (NY/T 1878-2010).

JB and JBC were purchased from Xuzhou Simaide Trading Co., Ltd. (Xuzhou, China). The JB originated from orchards of regularly pruned jujube trees during winter to save nutrient consumption and ensure the smooth overwintering of jujube trees. According to the producer, the JBC is produced by the pyrolysis and hardening of the JB in an SXGT-1000 rotary drum type carbonization furnace (Sanxiong Heavy Industry, Zhengzhou, China) at temperatures of $300-400{ }^{\circ} \mathrm{C}$ and a heating rate of approximately $2{ }^{\circ} \mathrm{C} / \mathrm{s}$. CC and $\mathrm{BM}$ were purchased from Dewoduo Fertilizer Co., Ltd. (Hengshui, China). The CC was produced by washing and crushing coconut shells, which were then dried and pressed into bricks. The $\mathrm{BM}$ was made by the steaming method, in which the animal bones were transferred into an autoclave and heated at $105-110{ }^{\circ} \mathrm{C}$. Steam was continuously supplied to the autoclave, and the bones were dried and crushed after most of the grease and gum were removed. Ultra-pure water (UW) was prepared using a Molro 40 economic water purifier (Molecular, Shanghai, China).

Table 1 reports the physicochemical properties of the raw materials. The moisture contents of all raw materials did not exceed $6 \mathrm{wt} \%$, which was within the optimal range of the densification requirements. The HHV (higher heating value) and bulk density of the JBC, obtained following pyrolysis, increased significantly due to the consumption of volatile components and the enhanced fixed carbon. This was reflected in the increased 
energy density by approximately 3.26 times compared to the JB. Additives are generally used to improve the physical stability of pellet that was blended and densified, as its lower energy density, and higher ash content may have a negative impact on the combustion performance of densified pellet [20], and thus the content of these additives in the pellet formulation need to be controlled to less than $10 \mathrm{wt} \%$ [21].

Table 1. Physicochemical properties of the raw materials used to produce pellets.

\begin{tabular}{|c|c|c|c|c|c|}
\hline \multirow{2}{*}{$\begin{array}{l}\text { Sample } \\
\text { Name }\end{array}$} & \multicolumn{5}{|c|}{ Proximate Analysis $\left(a^{a}, w_{t} \%\right)$} \\
\hline & $\mathbf{M C}^{\mathbf{b}}$ & VM & ASH & \multicolumn{2}{|c|}{ FC } \\
\hline $\mathrm{JB}^{\mathrm{c}}$ & $5.45 \pm 0.62$ & $84.53 \pm 0.59$ & $1.84 \pm 0.23$ & \multicolumn{2}{|c|}{$8.19 \pm 0.62$} \\
\hline JBC & $2.45 \pm 1.16$ & $38.13 \pm 0.97$ & $4.37 \pm 0.04$ & \multicolumn{2}{|c|}{$55.05 \pm 1.16$} \\
\hline $\mathrm{CC}$ & $5.36 \pm 0.88$ & $61.28 \pm 0.38$ & $15.21 \pm 0.81$ & \multicolumn{2}{|c|}{$18.15 \pm 0.88$} \\
\hline $\mathrm{BM}$ & $0.72 \pm 0.23$ & $17.37 \pm 0.10$ & $81.90 \pm 0.23$ & \multicolumn{2}{|c|}{$0.01 \pm 0.23$} \\
\hline \multirow{2}{*}{$\begin{array}{l}\text { Sample } \\
\text { Name }\end{array}$} & \multicolumn{5}{|c|}{ Ultimate Analysis (ar, wt\%) } \\
\hline & $\mathbf{N}$ & $\mathrm{C}$ & $\mathbf{H}$ & $\mathbf{O}$ & $\mathrm{S}$ \\
\hline JB & 5.75 & 50.41 & 6.11 & 35.85 & 0.48 \\
\hline JBC & 1.81 & 42.61 & 7.80 & 46.20 & 0.44 \\
\hline $\mathrm{CC}$ & 2.15 & 44.74 & 6.08 & 44.40 & 0.16 \\
\hline $\mathrm{BM}$ & 2.86 & 37.84 & 8.13 & 47.82 & 0.89 \\
\hline $\begin{array}{l}\text { Sample } \\
\text { Name }\end{array}$ & $\begin{array}{l}\text { HHV d } \\
(\mathrm{MJ} / \mathrm{kg})\end{array}$ & \multicolumn{2}{|c|}{$\begin{array}{l}\text { Bulk Density } \\
\left(\mathrm{kg} / \mathrm{m}^{3}\right)\end{array}$} & \multicolumn{2}{|c|}{$\begin{array}{c}\text { Energy Density } \\
\left(\mathrm{G} J / \mathrm{m}^{3}\right)\end{array}$} \\
\hline JB & 18.67 & \multicolumn{2}{|c|}{250} & \multicolumn{2}{|c|}{4.67} \\
\hline JBC & 31.84 & \multicolumn{2}{|c|}{490} & \multicolumn{2}{|c|}{15.60} \\
\hline $\mathrm{CC}$ & 17.45 & \multicolumn{2}{|c|}{140} & \multicolumn{2}{|c|}{2.44} \\
\hline $\mathrm{BM}$ & 2.93 & \multicolumn{2}{|c|}{950} & \multicolumn{2}{|c|}{2.78} \\
\hline
\end{tabular}

a $\mathrm{Ar}$ as received basis. ${ }^{\mathrm{b}} \mathrm{MC}$ : Moisture content; VM: Volatile content; ASH: Ash content; FC: Fixed carbon. ${ }^{\mathrm{c}} \mathrm{JB}$ : The pruned jujube tree branches; JBC: The charcoal of the pruned jujube tree branches; CC: Coco coir; BM: Bone meal. ${ }^{\mathrm{d}}$ HHV: Higher heating value.

\subsection{Pre-Treatment of Raw Materials}

Prior to the preparation of the densified pellet, the raw materials were pretreated by crushing and sieving. First, the raw materials were processed into lumps less than $10 \mathrm{~mm}$ in diameter using pruning shears and a hand hammer. Following this, $1.5 \mathrm{~kg}$ of raw materials were weighed and placed into an RS-FS1811 high-speed grinder (Royalstar, Hefei, China) for full pulverization. The crushed raw materials were then sieved using a ZDS-05 vibrating screening machine (OLAD, Quanzhou, China). The standard sieves were installed from top to bottom with a $10(0.85-2.00 \mathrm{~mm}), 20(0.60-0.85 \mathrm{~mm}), 30(0.18-0.60 \mathrm{~mm})$, and 80 $(<0.18 \mathrm{~mm})$ mesh. The sieved raw materials were weighed, and the volume was measured to calculate the bulk density.

\subsection{Optimization of Pellet Formulation}

\subsubsection{Densification Process}

The particles of the different raw materials (densification of some samples required the addition of UW) with a total weight of $1.00 \mathrm{~g}$ were initially mixed proportionally in a $\varphi 40 \mathrm{~mm}$ jar, and, subsequently, mixed thoroughly using an XH-C vortex mixer (AICE, Taizhou, China). The mixed raw materials were densified using a 769YP-30T manual powder tablet press (REOTAI, Guangzhou, China) with an alloy steel mold [22]. The inner diameter of the alloy steel mold was $\varphi 15 \mathrm{~mm}$, with a loading zone height of $50 \mathrm{~mm}$. The densification process was carried out at ambient temperature with a uniform manual pressure of $144 \mathrm{MPa}$ [23]. After holding the pressure for $90 \mathrm{~s}$, the pellet samples were removed using an ejector [23]. The as-prepared samples were stabilized for 15 min in air, then weighed using an FA2204C analytical balance (Techcomp, Shanghai, China), and their external dimensions were measured using a digital vernier caliper. Finally, the samples 
were labeled, the pellet density was calculated, and they were subsequently sorted and stored in sealed bags.

\subsubsection{Experimental Design}

The storage and transportation performance of a pellet are two crucial factors determining its industrialization potential; the combustion performance and cost effectiveness of the pellet are also essential for determining its suitability for industrialization. Hence, the experimental process was divided into three stages: (1) parameter range screening tests were employed to investigate the influence of individual factors on the storage and transportation performance of samples and to determine the factor level range required for the optimization test; (2) pellet formulation optimization tests were designed to evaluate the interaction effect of various factors on the storage and transportation performance of samples, and determined the optimized formula parameters in combination with their combustion performance; and (3) the pellet formulation comparison test was conducted to compare the storage and transportation characteristics, combustion characteristics and cost-effectiveness of different pellet samples to validate the superiority of pellet.

During the storage and transportation processes, the pellet may gradually break due to vibration, extrusion, etc., which can cause soil contamination and waste dispersion, and negatively impact its combustion efficiency. Hence, it is necessary to improve the physical stability of pellet [24]. In this study, drop resistance was employed as the primary evaluation index of the physical stability, and the primary indicator of storage and transportation performance. For the physical stability tests, the samples were subjected to free drop motion at a height of $1.85 \mathrm{~m}$ onto the steel plates on the ground, with each sample hitting the steel plate three times. The mass ratio percentage of the sample before and after the drop was used to indicate the physical stability of the pellet. Test results with values greater than or equal to $98 \%$ indicated that the pellet sample met the standard. The pellet density was employed as the secondary indicator of storage and transportation performance. According to the recommended standard of the Ministry of Agriculture of China (NY/T 1878-2010), the pellet density should be greater than or equal to $1000 \mathrm{~kg} / \mathrm{m}^{3}$ [25].

Table 2 reports the factors, levels, and formulation parameters for each stage of the drop test. In the parameter range screening test, JB particles with a particle size $\varphi<0.18 \mathrm{~mm}$ (80 mesh) were employed as the main raw materials in the first group of tests, and no additives were included. In the second group of tests, the JBC content in the secondary raw materials was maintained at $20 \mathrm{wt} \%$ without additives, while in the third group, $10 \mathrm{wt} \%$ additives were added based on the parameters of the previous two groups.

The pellet formulation optimization tests were performed using a four-factor, threelevel orthogonal test. Orthogonal testing employs mathematical statistics to rationalize the test procedure [26]. This method can significantly reduce the number of tests without losing test information and is able to simultaneously analyze multiple factors and their interactions. The optimized formula parameters were obtained by the variance and range analysis of test results. The variance analysis decomposes the sum of squares of the total variance and subsequently performs statistical tests [27] to determine the influence of the controllable factors on the test index. Range refers to the maximum difference between the test results of each factor at different levels. By comparing the range of each factor, the order of magnitude can be used to determine the primary and secondary effects of each factor [28]. Based on the results of the range and the variance analysis, the JBC content was increased to the maximum value to obtain the optimal formula parameters of the highest JBC content.

The pellet formulation comparison tests were conducted to compare the characteristics of samples without JBC and additives according to the above optimal formulation and to analyze the differences and reasons through characterization. In Table 2, the samples are named in the form of $\mathrm{JB}+$ number $1+($ number 2$)+\mathrm{C}+$ number $3+$ additive type. For example, JB56(80)-C37-CC means that the sample consists of 80 mesh JB with a mass fraction of $56 \mathrm{wt} \%$, and JBC with a mass fraction of $37 \mathrm{wt} \%$, with CC as the additive. For 
the three-stage experiment, all tests were repeated three times for each sample, and the mean and standard deviations were calculated.

Table 2. Factors, levels, and formula parameters of the three-stage experiment.

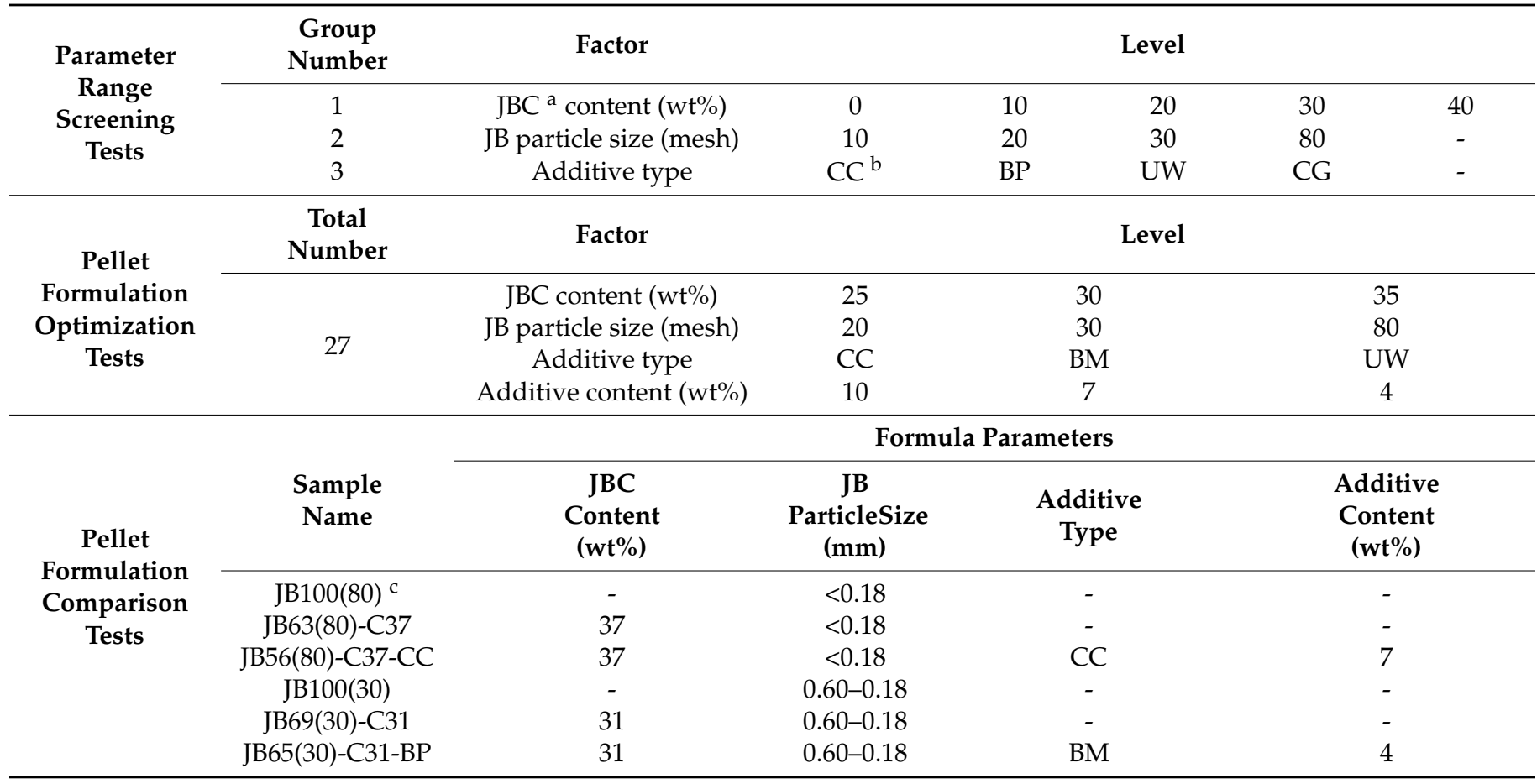

a JB: The pruned jujube tree branches; JBC: the charcoal of the pruned jujube tree branches. ${ }^{\mathrm{b}}$ CC: Coco coir; BM: Bone meal; UW: Ultra-pure water; CG: Control group. ${ }^{\mathrm{C}}$ The samples are named in the form of JB + number $1+$ (number 2) + C + number 3 + additive type. For example, JB56(80)-C37-CC means that the sample consists of 80 mesh JB with a mass fraction of $56 \mathrm{wt} \%$, and JBC with a mass fraction of $37 \mathrm{wt} \%$, with CC as the additive.

\subsection{Characterization}

Proximate and elemental analyses were performed on the raw materials. The former adopted the analytical methods of the American Society for Testing and Materials (ASTM 1762-84 and 3173-87) [29], and the latter was conducted via a vario PYRO elemental analyzer (Elementar, Langenselbold, Germany). Higher Heating Value (HHV) measurements of raw materials and samples were obtained using an LC-VC-430 automatic calorimeter (UCHEN, Shanghai, China). The bulk density of raw materials was measured using a $500 \mathrm{~mL}$ density cup, while the pellet density of samples was calculated by the ratio of mass to volume [30]. The energy density of raw materials and samples was taken as the product of bulk density or pellet density and HHV.

The moisture absorption behavior of the samples was measured using an HWS-158 constant temperature and humidity incubator (Ningbo Southeast Instrument Co., Ltd., Ningbo, China). The samples were dried in a DHG-9070AS incubator (Ningbo Southeast Instrument Co. Ltd., Ningbo, China) at $105^{\circ} \mathrm{C}$ for $12 \mathrm{~h}$ to remove the internal moisture, and then transferred into an incubator operated at the relative humidity of $70 \%$ at $30{ }^{\circ} \mathrm{C}[31,32]$. The samples were weighed many times over a period of $32 \mathrm{~h}$ and tested for pellet. Each formulation was repeated three times. The moisture content was then calculated based on the changes in the sample weights.

Infrared spectra of the raw materials and samples were collected using an FT-IR spectrometer (Nicolet iS20, Thermo Scientific, Waltham, MA, USA). The materials were scanned in the range of $4000-400 \mathrm{~cm}^{-1}$ with a resolution of $4 \mathrm{~cm}^{-1}$ in transmission mode and 16 scan per spectrum. Thermogravimetric (TG) and differential thermogravimetric (DTG) analyses were performed on the raw materials and samples using a TG-209-F3 Tarsus thermal analyzer (NETZSCH, Selb, Germany). Approximately 15-20 mg of samples 
were heated from ambient temperature to $800^{\circ} \mathrm{C}$ at a constant heating rate of $10^{\circ} \mathrm{C} / \mathrm{min}$ under an oxygen atmosphere with a $50 \mathrm{~mL} / \mathrm{min}$ flow rate.

\section{Results and Discussion}

\subsection{Analysis of Raw Materials}

\subsubsection{Particle Size and Density Distribution}

The particle size and bulk density of raw materials have important impacts on the physical stability of the densified pellet [33]. As shown in Figure 1a, the relative contents of JB particles with different particle sizes were prevalent in all four intervals after full grinding, and the bulk density increased significantly with decreasing particle size. For the ease of densification, all materials, including the JBC and the additives, were pre-screened to unify the particles size. After the pre-screening, it was found that most of the materials reached the particle size of less than 80 mesh $(\leq 0.18 \mathrm{~mm})$. Specifically, $98.00 \mathrm{wt} \%$ for both the JBC and $\mathrm{BM}$ and $79.69 \mathrm{wt} \%$ for CC falls in the particle range size of less than 80 mesh, which is shown in Figure 1b. The bulk density of the JBC and BM within the 80 mesh was observed to be 1.17 and 2.29 times compared to that of the JB, while the bulk density of CC was only $32.71 \%$ of JB, respectively. This reveals the necessity to fully consider the effect of the JB with different particle sizes on the pellet performance during the densification process. The concentrated particle size distribution of the remaining raw materials can help simplify the formulation process.

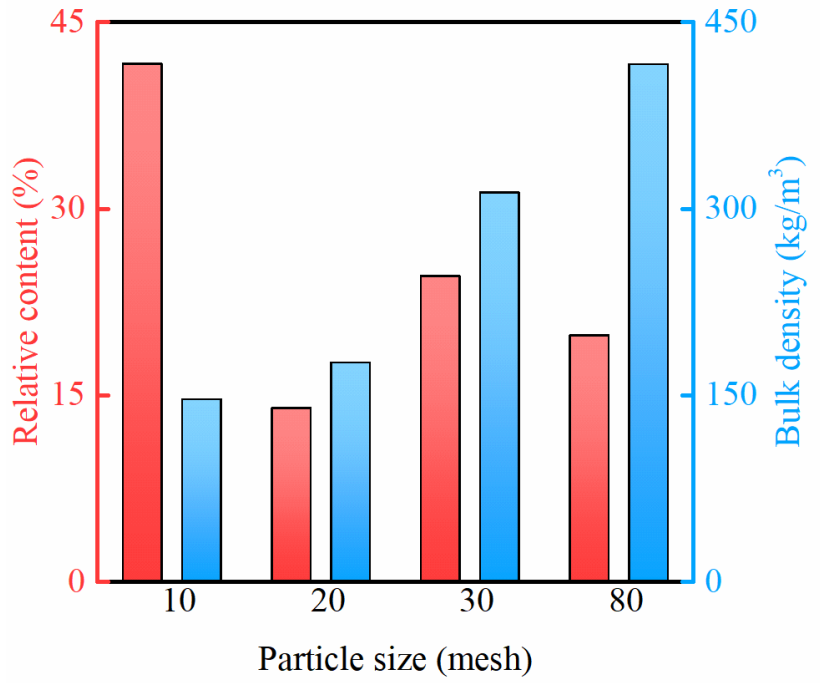

(a)

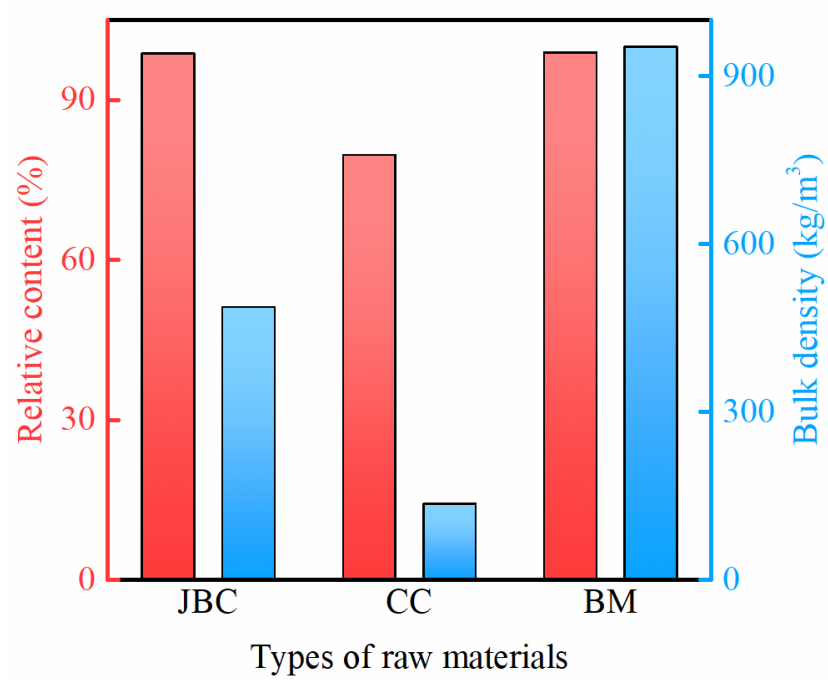

(b)

Figure 1. Particle size distributions and bulk densities of raw materials: (a) Data on JB; (b) Data on JBC, CC, and BM. JB: The pruned jujube tree branches; JBC: The charcoal of the pruned jujube tree branches; CC: Coco coir; BM: Bone meal.

\subsubsection{Functional Groups}

Figure 2 shows the FT-IR spectra of the raw materials. The hydroxyl-OH stretching vibration was observed around $3400 \mathrm{~cm}^{-1}$ [34], and the peak on the spectrum of JBC was significantly lower than that of the JB. This is attributed to the breakage of the hydrogenbonded hydroxyl group following the carbonization of the JB, resulting in the detachment of bound water. Aliphatic C-H stretching vibrations [35] were observed around $2920 \mathrm{~cm}^{-1}$. The peak at $1035 \mathrm{~cm}^{-1}$ corresponds to C-O-C stretching vibrations, where the characteristic JBC peak weakened due to the dehydrogenation and deoxygenation of the JB during the carbonization process [36]. The out-of-plane aromatic $\mathrm{C}-\mathrm{H}$ bending vibration of the JBC was clear within the region $987-781 \mathrm{~cm}^{-1}$, indicating an intensification in the dehydrogenation reaction during the carbonization process and an enhancement in the aromatization structure [37]. The bending vibration of aliphatic C-H around $1383 \mathrm{~cm}^{-1}$ indicated the 
formation of intermediate decomposition products and the polymerization of cellulose and lignin contained in the JBC [38]. The carbonyl functional groups $\mathrm{C}=\mathrm{O}$ of esters were observed around $1739 \mathrm{~cm}^{-1}$, and the stretching vibrations of aromatic rings in the lignin were present around $1509 \mathrm{~cm}^{-1}$ [39]. These peaks were absent in the JBC due to carbonization and decomposition. The $897 \mathrm{~cm}^{-1}$ and $781 \mathrm{~cm}^{-1}$ peaks of the JB and JBC, respectively, indicate a gradual shift of $\mathrm{C}-\mathrm{H}$ in the aromatic ring structure to a lower wave number, resulting in the breakage of the lignin aromatic ring structure and the generation of more free radicals [40]. This is an overlap of the - $\mathrm{OH}$ stretching vibrations of surface-free water and calcium hydroxy-phosphate. Additional peaks were observed at 1442 and $870 \mathrm{~cm}^{-1}$, $1030 \mathrm{~cm}^{-1}$, and 694 and $536 \mathrm{~cm}^{-1}$, corresponding to $\mathrm{CO}_{3}{ }^{2-}$, the stretching vibrations of $\mathrm{PO}_{4}{ }^{3-}$, and the bending vibrations of $\mathrm{P}-\mathrm{O}$, respectively.

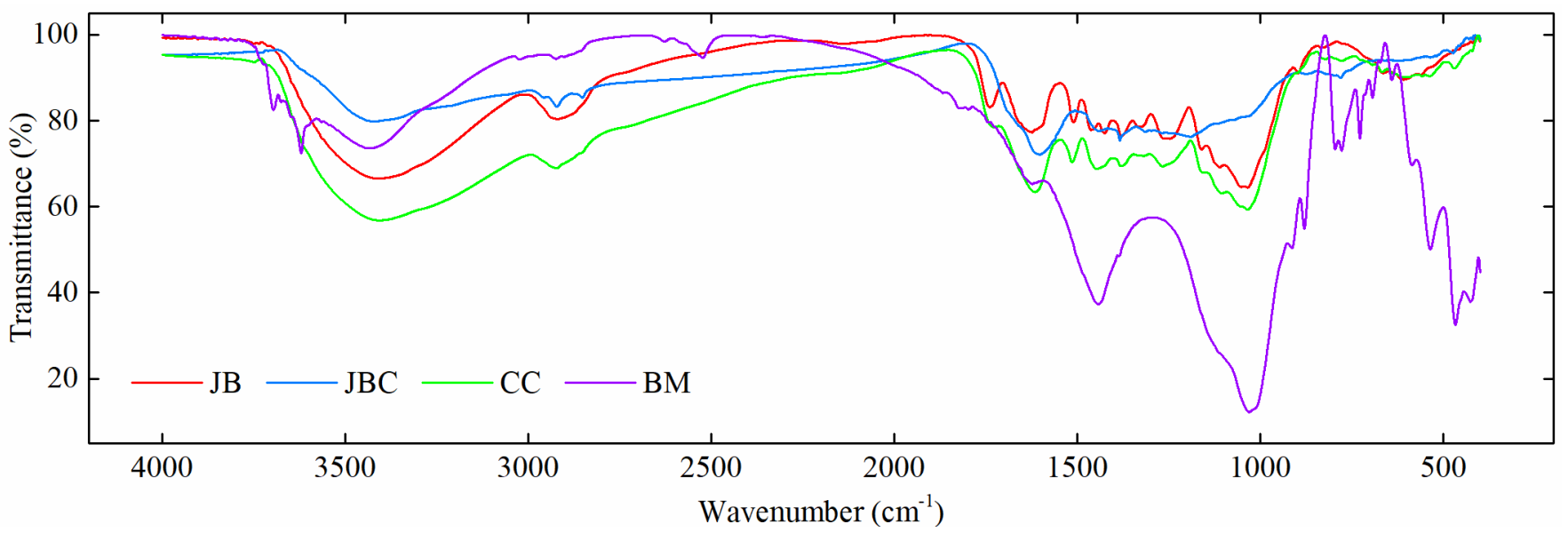

Figure 2. FT-IR spectra of the raw materials. JB: The pruned jujube tree branches; JBC: The charcoal of the pruned jujube tree branches; CC: Coco coir; BM: Bone meal.

\subsubsection{Thermogravimetric Analysis}

Figure 3 presents the combustion characteristics of raw materials investigated via thermogravimetric analysis. The TG curves of the JB and CC were essentially similar, indicating the similar combustion processes between the two, with the main difference being that the residue of the final non-combustible substances of the CC was about 2.00 times that of the JB (Figure 3a). The major mass loss temperature zone of JBC was significantly delayed compared to that of the JB, which indicated that the combustion of the JBC mainly occurred at higher combustion temperature. This is because the volatile component in the JBC was relatively low after the carbonization. The TG curve of the BM was significantly different to the other three biomass types in that there was no water evaporation phase, and slow changes were observed in the volatile component release and combustion phase. The residue from BM generally did not contain fixed carbon, with a residual mass of $84.05 \mathrm{wt} \%$, the main components being calcium phosphate and calcium carbonate that had not reached their melting points. This is essentially consistent with the ash content of BM in Table 1 $(81.90 \pm 0.23 w t \%)$.

Figure $3 \mathrm{~b}$ depicts the DTG curves of the raw materials. By combining the TG curves with the ignition temperatures, burnout temperatures and burning times were calculated [41]. The ignition temperatures of the JB and JBC were determined as $271.6^{\circ} \mathrm{C}$ and $379.3^{\circ} \mathrm{C}$, respectively, with the $100{ }^{\circ} \mathrm{C}$ difference indicating that JBC was more difficult to ignite due to the absence of volatile components. The ignition temperatures of $\mathrm{CC}$ and $\mathrm{BM}$ were $259.6^{\circ} \mathrm{C}$ and $652.7^{\circ} \mathrm{C}$, respectively. The JB and CC exhibited two characteristic peaks, representing the volatile component release and combustion phase and fixed carbon combustion phase, respectively [42]. Unlike the CC, the volatile component release and combustion phase of the JB were highly reactive, while the fixed carbon combustion phase was moderate. This was consistent with the results of the proximate analysis. The JBC, 
which lacked volatile components due to carbonization, exhibited a single relatively smooth characteristic peak, indicating that the combustion process of the JBC was both gentle and highly persistent.

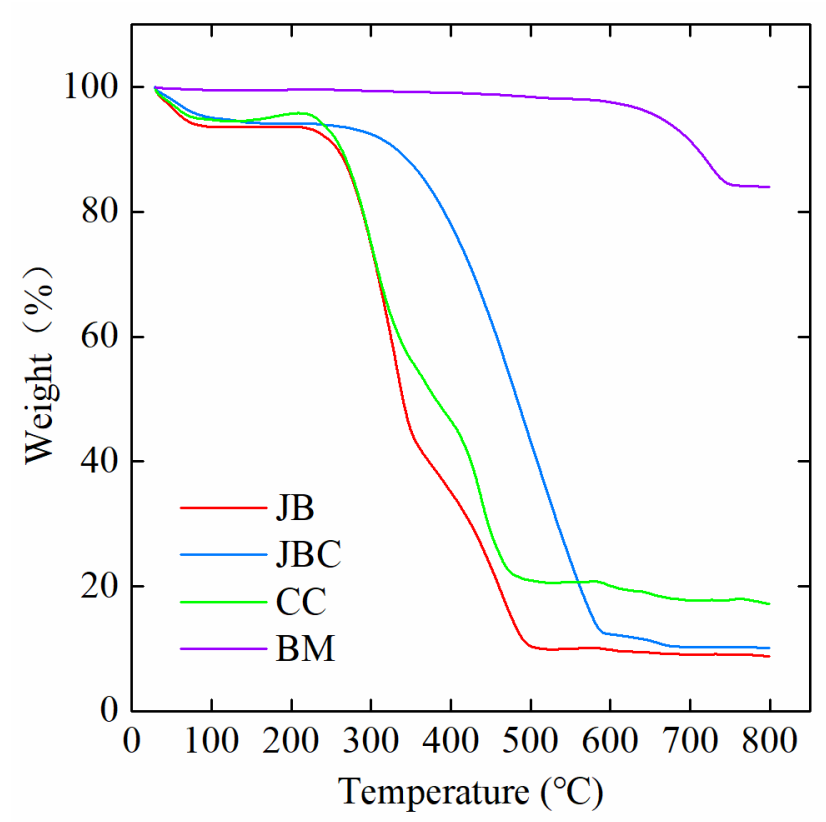

(a)

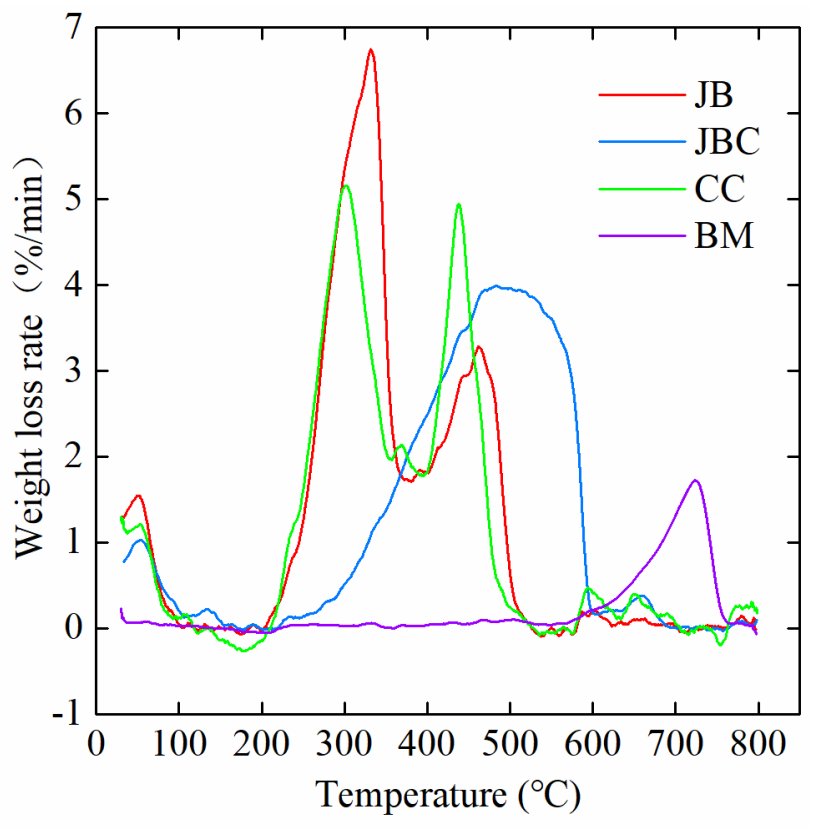

(b)

Figure 3. Thermogravimetric analysis of raw materials: (a) TG curve; (b) DTG curve. JB: The pruned jujube tree branches; JBC: The charcoal of the pruned jujube tree branches; CC: Coco coir; BM: Bone meal.

\subsection{Optimization of Formula Parameters}

\subsubsection{Parameter Range Screening}

Optimization of JBC Contents

The drop resistance and pellet density of samples were found to be negatively correlated with the JBC content (Figure 4). Specifically, as the JBC content increased, the drop resistance and pellet density of the samples decreased. When the JBC content was $20 \mathrm{wt} \%$, the samples were in a critical state. Namely, the drop resistance was $98.14 \%$, meeting the physical stability requirement. This corresponded to a pellet density of $994 \mathrm{~kg} / \mathrm{m}^{3}$, which was slightly lower than the standard of the Ministry of Agriculture of China (NY/T 18782010). As the JBC content increased, the standard deviation of the drop resistance and pellet density also expanded, and the storage and transportation performance of the samples gradually deteriorated. When the JBC content increased to $40 \mathrm{wt} \%$, the drop resistance of the samples reduced significantly to $77.55 \pm 10.18 \%$. The difficulty of densifying between the JB particles was reduced by the lubricating effect of the moisture. In addition, the densifying was stabilized by the gradual increase in the lignocellulose surface viscosity via warming and softening under high pressure, followed by cooling to form a solid bridge [43]. The addition and mixing of smaller-sized JBC particles resulted in the brittleness and hydrophobicity of the JBC particles and the lack of viscosity after pyrolysis, preventing water flow and the mutual contact between JB particles with increasing JBC content. Thus, the particles could not adhere together to form sufficient solid bridges, resulting in the inability to form stable pellet. This was clear when the JBC content increased to $40 \mathrm{wt} \%$, and the drop resistance of the samples was no longer able to meet the commercialization requirements $(77.55 \pm 10.18 \%)$. 


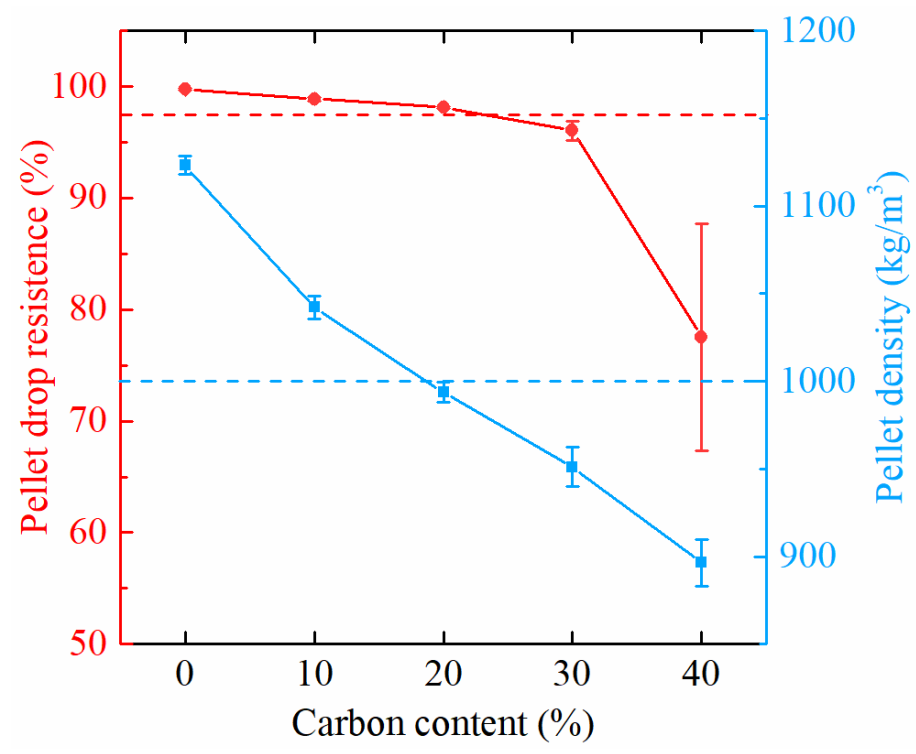

Figure 4. Effects of different JBC contents on the storage and transportation characteristics of the pellets. JBC: The charcoal of the pruned jujube tree branches.

\section{Optimization of JB Particle Sizes}

At the JBC content of $20 \mathrm{wt} \%$, the drop resistance and pellet density of the samples varied with the JB particle size (Figure 5). The drop resistance and pellet density values peaked at the JB particle size of 30 mesh. The drop resistance of the JB particle sizes in the first two groups all exceeded $98 \%$, while the pellet density was observed to be approximately $99.4 \%$ of the required standard value, meeting the physical stability requirements. During the densifying process, the JB particles were stacked on top of each other, and the surfaces were in full contact. For larger particle sizes, the drop resistance of the JB particles decreased. The possible reasons for this are twofold. First, the surfaces of larger JB particles were not in full contact with each other, with a greater number of voids in the center. This affected the flow of water and the formation of solid bridges. Second, owing to the elongated structure of lignocellulose, the larger the JB particle size, the higher the elastic modulus, and the greater the power consumption required to resist the internal elastic potential energy under the same compression parameters. Consequently, this complicated the densifying processes. When the JB particle size was 80 mesh, the drop resistance of the pellet was slightly lower than that of the pellet produced with the 30-mesh size JB particle. Despite the lower elastic potential energy of the 80-mesh size JB particles, the overlap of its substrate frame was affected by JBC particles of the same particle size, and rather than the JBC particles filling the frame gaps, they replaced the 80-mesh size JB particles as the framework. The JBC particles lacked the binding characteristics of the JB particles, thus reducing the overall strength of the pellet.

\section{Effect of Additives}

Figure 6 depicts the performance of the drop resistance and pellet density of the samples in different additive and control groups, with an 80 mesh JB particle size, $20 \mathrm{wt} \%$ JBC content, and $10 \mathrm{wt} \%$ additive content. The addition of UW, BM, and CC all increased the drop resistance of the pellet samples, with their effectiveness, from lowest to highest, in the order of UW $(98.38 \%)<$ BM $(99.22 \%)<$ CC $(99.69 \%)$. The slight increase in strength via the addition of UW is related to the improved lubrication between the particles during densification following the external moisture replenishment, which reduced the energy consumption and resulted in tighter densifying. In the functional group analysis, the BM was observed to contain a low content of hydroxyl groups. Therefore, the BM exhibited a good hydrophilicity and facilitated the flow of internal water for lubrication and enhancing densification. Despite the similar particle sizes between the CC and JB, its longitudinal 
dimension was relatively longer. This improved the overall strength of the pellet by linking the polymeric agglomerates of particles that were close to each other but had insufficient surface contact when the blended particles were stacked on top of each other. A positive correlation was observed between the effect of the CC and BM on the pellet density $\left(1020 \mathrm{~kg} / \mathrm{m}^{3}\right.$ and $\left.1070 \mathrm{~kg} / \mathrm{m}^{3}\right)$, while UW was found to negatively impact the pellet density $\left(900 \mathrm{~kg} / \mathrm{m}^{3}\right)$. This negative correlation is attributed to the excessively large $10 \mathrm{wt} \%$ ratio. The excess water was squeezed out from the mold gap during the densifying process, resulting in an overall loss of mass. The highest density of pellet with BM additives was attributed to the bone meal density $\left(1000 \mathrm{~kg} / \mathrm{m}^{3}\right)$. Although the density of pellet with CC additives was lower; it increased the densifying strength and reduced the JBC loss.

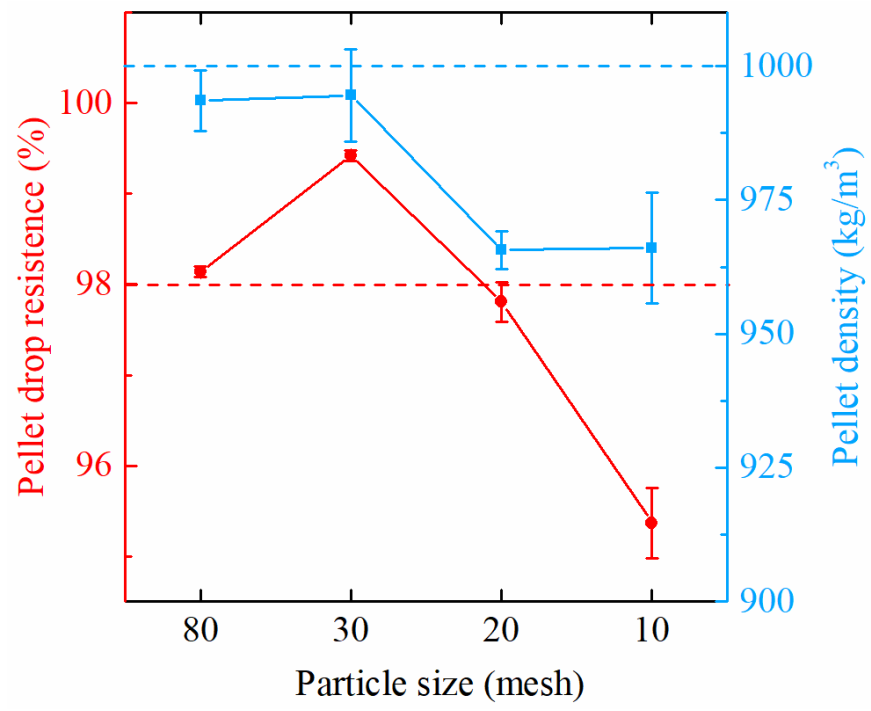

Figure 5. Effects of different JB particle sizes on the storage and transportation characteristics of the pellets. JB: The pruned jujube tree branches.

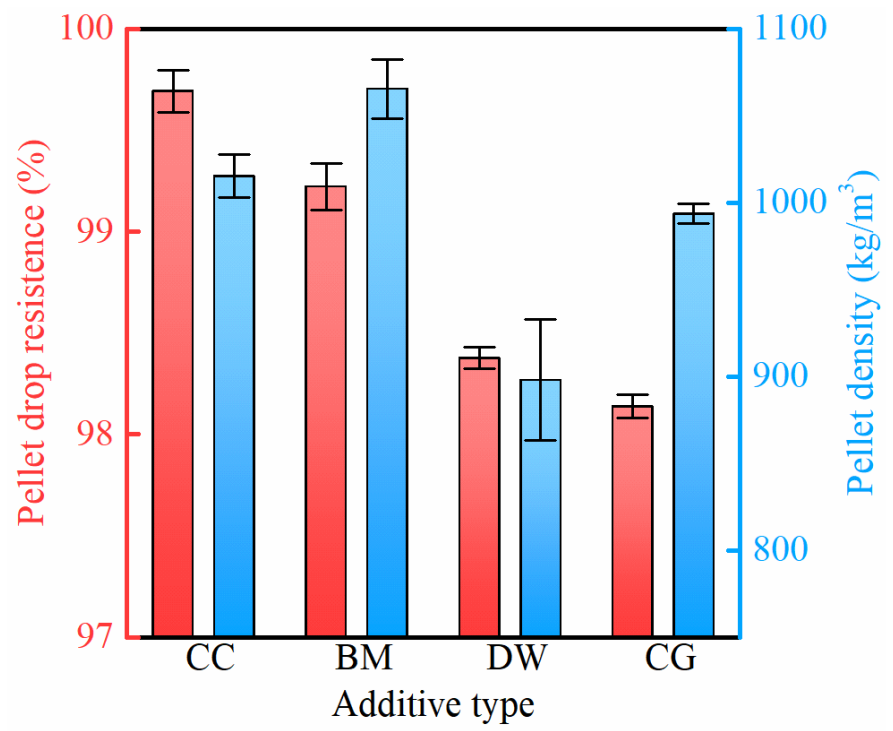

Figure 6. Effects of different additives on the storage and transportation characteristics of the pellets. CC: Coco coir; BM: Bone meal; UW: Ultra-pure water; CG: Control group.

\subsubsection{Pellet Formulation Optimization}

Experimental Results

Orthogonal tests were employed for the parameter optimization based on 27 samples (each sample was repeated three times) using four-factor, three-level interaction tests 
(Figure 7). A total of 18 groups exhibited drop resistance values greater than or equal to $98 \%$, and 7 groups with particle densities greater than or equal to $1000 \mathrm{~kg} / \mathrm{m}^{3}$. The results reveal the great influence of the different JBC contents, JB mesh numbers, additive types, and dosage combinations on the physical stability of pellets. In order to further analyze the relationships between these variables, variance and range analyses were performed. The drop resistance, which represents physical stability, was the primary control index of this study, and thus the focus of the analysis. Based on ensuring the drop resistance, the pellet formulation was optimized using the drop resistance and the pellet density.

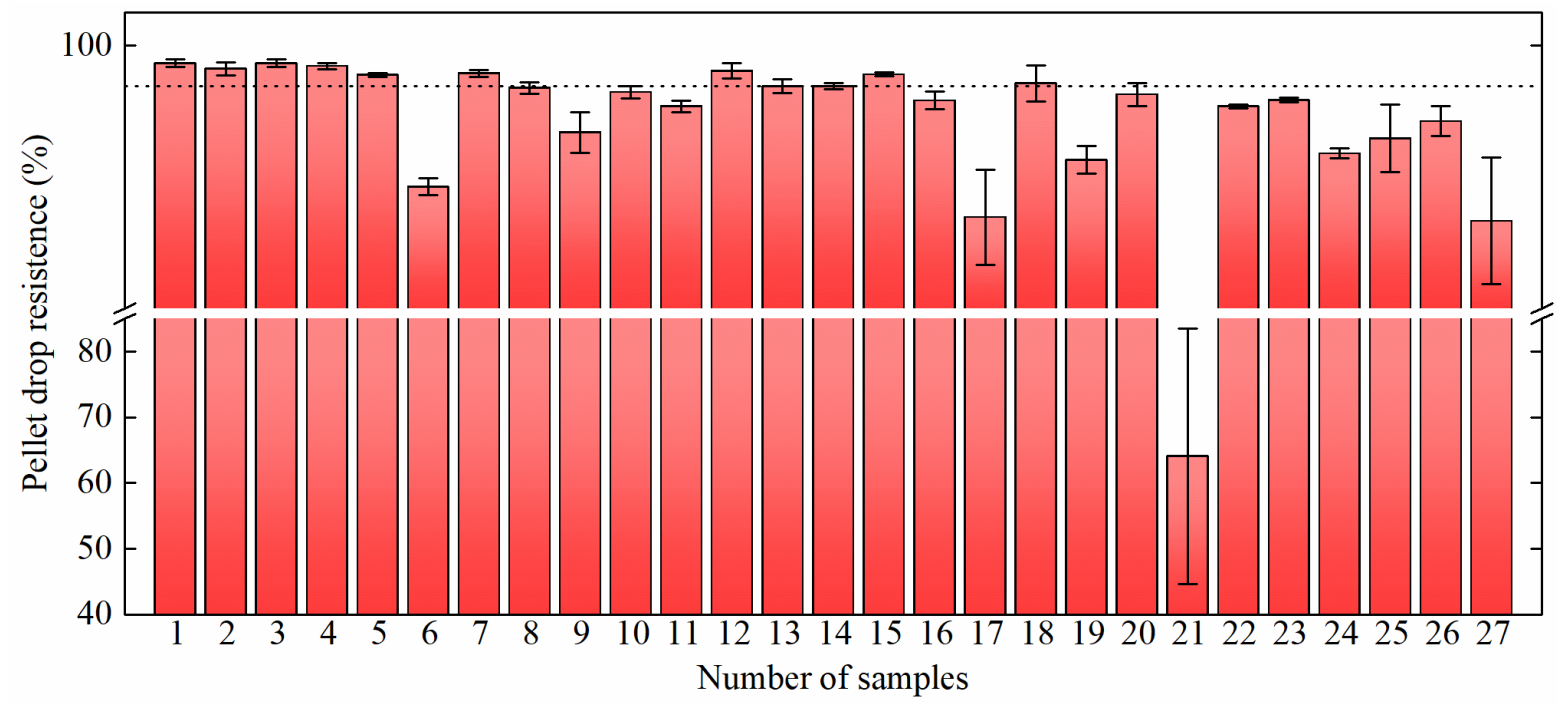

(a)

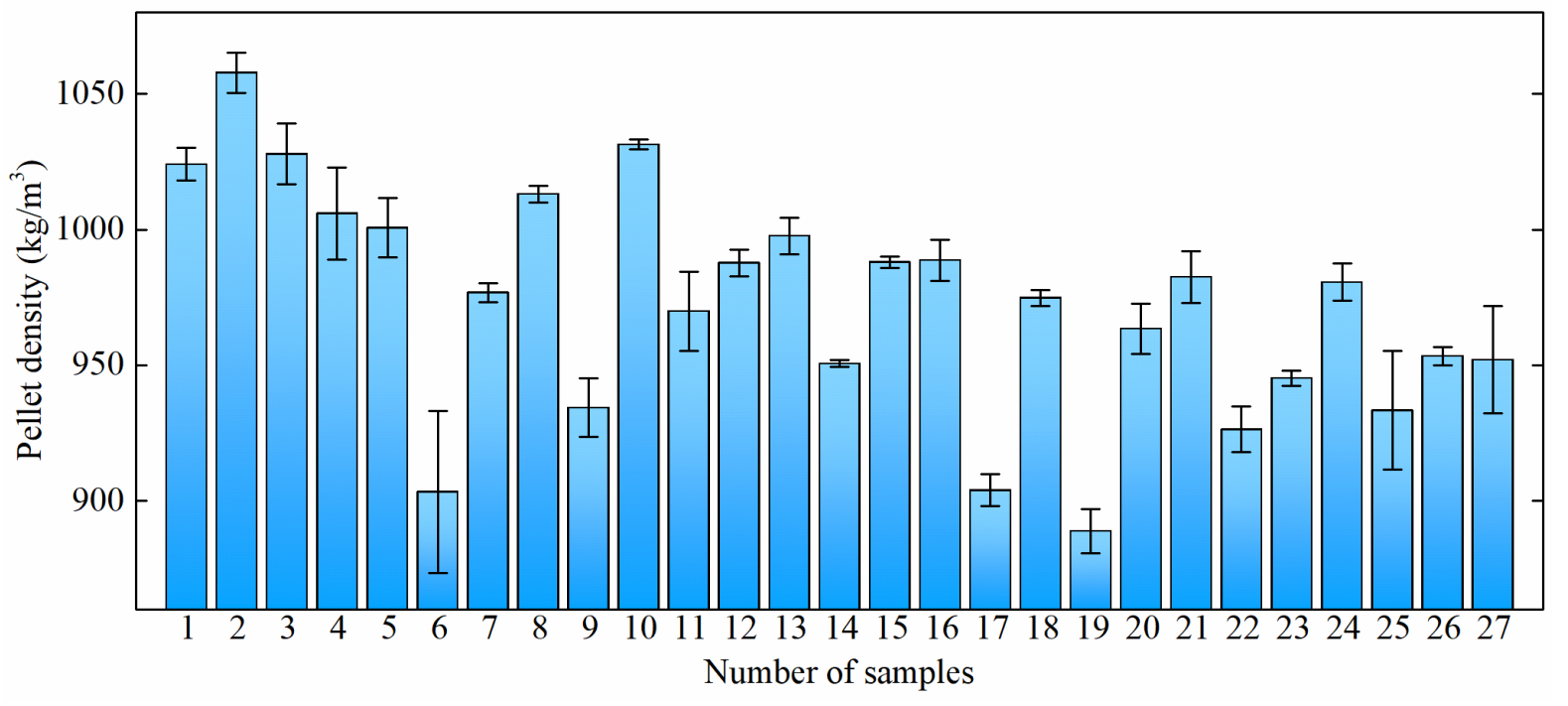

(b)

Figure 7. Results of the formulation optimization: (a) Pellet drop resistance; (b) Pellet density.

Variance Analysis

IBM SPSS Statistics 22 software was used to analyze the variance of the test results. Table 3 reports the variance analysis results of the drop resistance. The influences of each factor and their interactions on the drop resistance of samples were: $A>A C>C>A D>B D$ $>\mathrm{BC}>\mathrm{CD}>\mathrm{AB}>\mathrm{B}>\mathrm{D}$, and all were highly significant $(p<0.01)$. The JBC content (A) was the most important factor affecting the drop resistance of samples. During densification, the moisture and volatiles, as natural binders between particles, play a very important role $[44,45]$. The JBC particles, lacking moisture and volatiles, adhered to the JB and solid 
additive particles. This hindered the flow and lubrication of the water, as well as the softening and bonding with other particles. Hence, the higher the JBC content (A), the more clear the damage to the drop strength of the samples. The drop resistance of the samples was significantly improved by adding the appropriate additives $(C)$ and controlling their content (D). The interaction between the JBC content and additive type and dosage (AC and AD) was also clear. The effect of the JB particle size (B) was not significant, neither was that of the additives ( $C$ and $D)$ and the interaction between them (BC and BD), which also indicated the importance of the additives ( $C$ and $D)$ in blending the densified pellet. This does not indicate that the JB particle size (B) was less influential, rather that it played a positive role in the underlying framework structure.

Table 3. Variance analysis results for the parameter optimization test.

\begin{tabular}{lccccc}
\hline \multicolumn{1}{c}{ Source } & $\begin{array}{c}\text { Sum of } \\
\text { Squares III }\end{array}$ & DF & $\begin{array}{c}\text { Mean } \\
\text { Square }\end{array}$ & F & P \\
\hline Modified model & $3478.553^{\mathrm{a}}$ & 26 & 133.790 & 9.359 & 0.00000 \\
Intercept & 759194.670 & 1 & 759194.670 & 53105.501 & 0.00000 \\
A: JBC ${ }^{\mathrm{b}}$ content $(\mathrm{wt} \%)$ & 437.407 & 2 & 218.704 & 15.298 & 0.00001 \\
B: JB particle size (mm) & 2.000 & 2 & 85.588 & 5.987 & 0.00448 \\
C: Additive type & 296.903 & 2 & 148.451 & 10.384 & 0.00015 \\
D: Additive content (wt $\%)$ & 163.104 & 2 & 81.552 & 5.705 & 0.00565 \\
AB & 208.997 & 2 & 104.498 & 7.310 & 0.00155 \\
AC & 344.141 & 2 & 172.070 & 12.036 & 0.00005 \\
AD & 245.629 & 2 & 122.814 & 8.591 & 0.00058 \\
BC & 221.672 & 2 & 110.836 & 7.753 & 0.00110 \\
BD & 222.472 & 2 & 111.236 & 7.781 & 0.00107 \\
CD & 212.987 & 2 & 106.493 & 7.449 & 0.00139 \\
Error & 771.982 & 54 & 14.296 & & \\
Total & 763445.205 & 81 & & & \\
Adjusted sum & 4250.535 & 80 & & & \\
\hline
\end{tabular}

$\overline{{ }^{a}} R^{2}=0.818$ (Adjusted $R^{2}=0.731$ ); ${ }^{b}$ JB: the pruned jujube tree branches; JBC: The charcoal of the pruned jujube tree branches.

\section{Range Analysis}

Figure 8 depicts the results of the range analysis of the parameter optimization test, where the ordinate represents the drop resistance of the sample; letters $A, B, C$, and $\mathrm{D}$ correspond to the four factors in the test, respectively; and the numbers 1,2 , and 3 after the letters are the levels of the corresponding factors, respectively. The optimization aimed to further improve combustion performance by increasing the JBC content while maintaining the storage and transportation performance. Combining the results of the variance analysis, two formulations were obtained: (a) A2C1D2B1: JBC content $30 \mathrm{wt} \%$, JB particle size 80 mesh, and CC additive content $7 \mathrm{wt} \%$; and (b) A2C2D3B2: JBC content $30 \mathrm{wt} \%$, JB particle size 30 mesh, BM additive content $4 \mathrm{wt} \%$. The drop resistance values of the formulations were $98.85 \%$ and $98.71 \%$, respectively.

\section{Optimized Formula Parameters}

The formula parameters obtained by the variance and range analyses, which are based on the set parameters of the test group, do not reflect the maximum JBC content limit that can be achieved under these conditions. In order to further improve the combustion performance of pellet, the target drop resistance was set as $\geq 98 \%$, and the JBC content was increased to the upper limit without changing the determined JB particle size, additive type, and content. A single-factor test was conducted with the initial value of JBC content set at $25 \mathrm{wt} \%$ and the addition of $2 \mathrm{wt} \%$ increments. The optimized parameters were as follows: (a) JB particle size- 80 mesh, CC content $-7 \mathrm{wt} \%$, and maximum JBC content-37 wt $\%$; and (b) JB particle size-30 mesh, BM content-4 wt $\%$, and maximum JBC content-31 wt $\%$. 

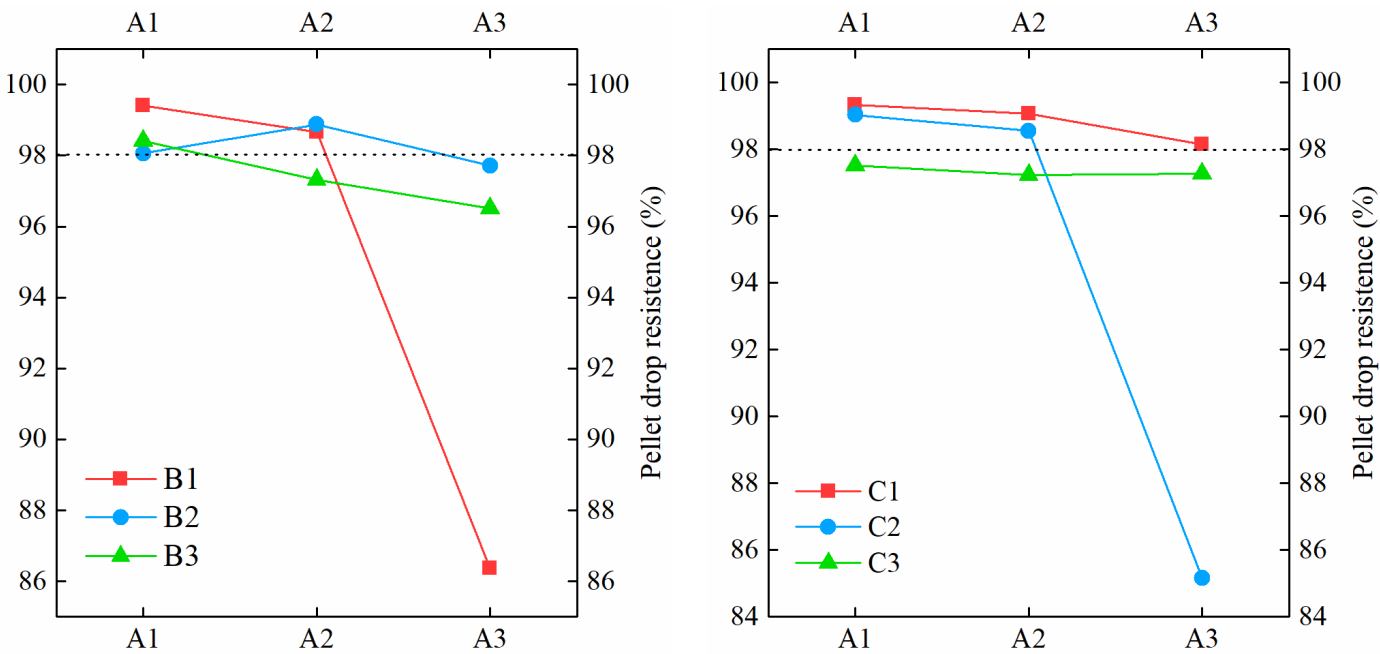

(a)

(b)
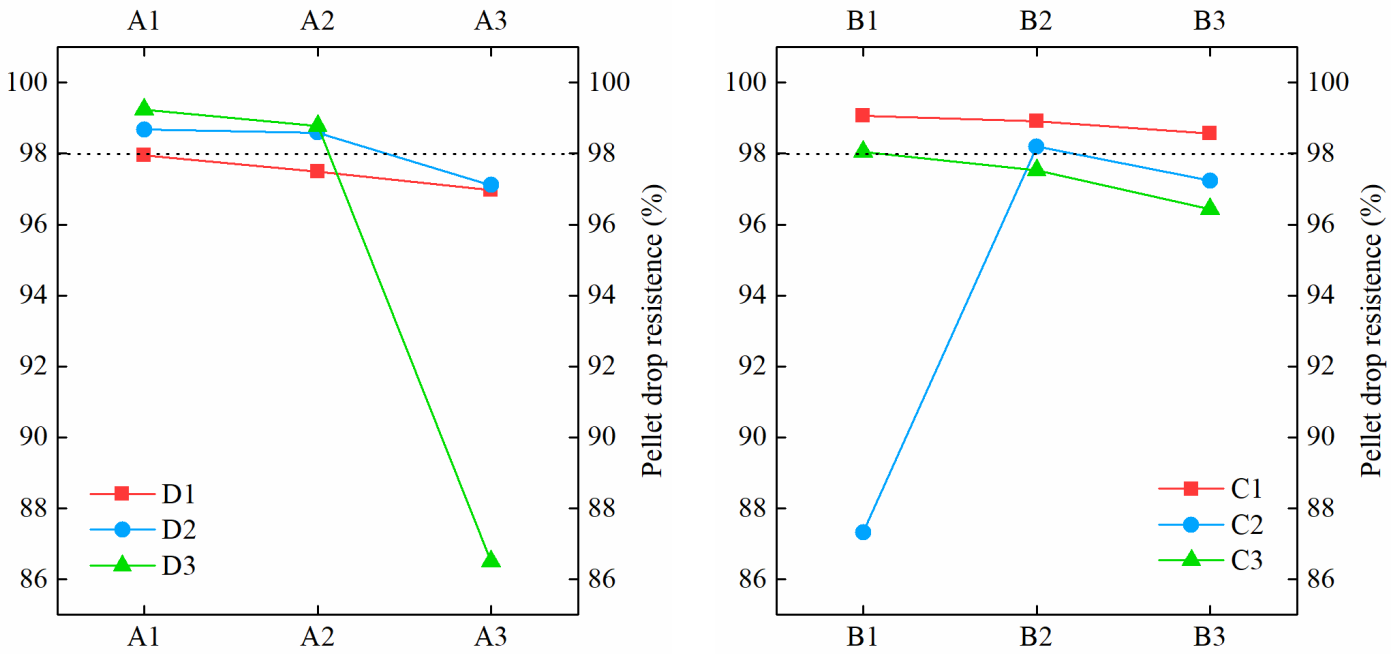

(c)

(d)

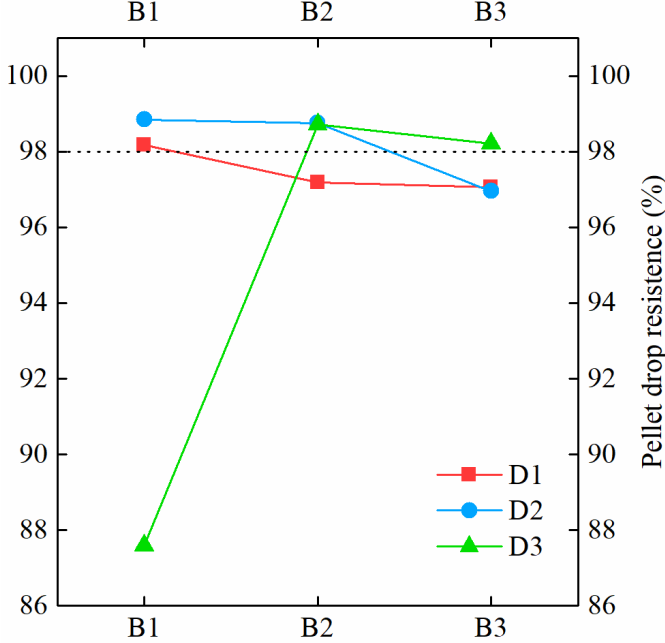

(e)

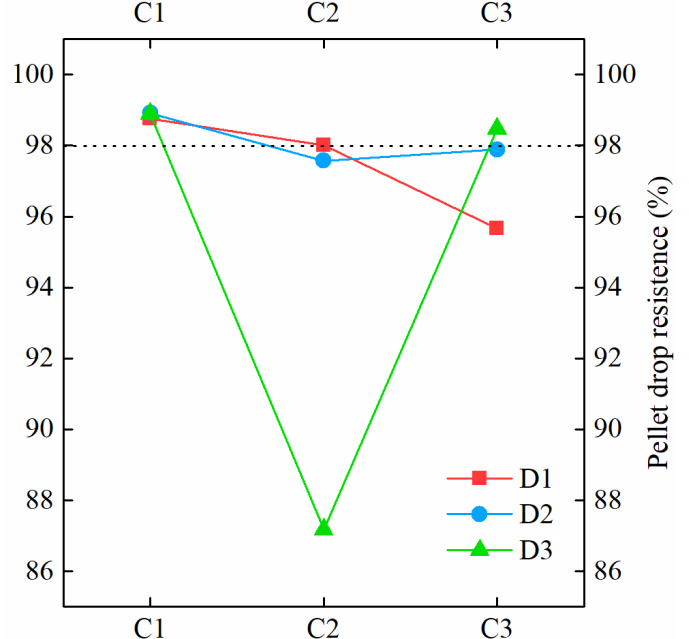

(f)

Figure 8. Range analysis results of the parameter optimization: (a) JBC content (A) and JB particle size (B); (b) JBC content (A) and additive type (C); (c) JBC content (A) and additive content (D); (d) JB particle size (B) and additive type (C); (e) JB particle size (B) and additive content (D); (f) Additive type $(C)$ and additive content $(D)$. 


\subsubsection{Pellet Formulation Comparison}

Test Results on Pellet Drop Resistance, Pellet Density, and Energy Density

The pellet samples prepared with two optimized formula parameters were compared with their related samples. Table 2 reports the specific sample numbers and formula parameters, while Figure 9 presents the experimental results of the drop resistance, pellet density, and energy density. As revealed in the analysis presented in Section 3.2.1 (Optimization of JBC Contents), the increased JBC content reduced the drop resistance and pellet density of the pellet samples. However, with the use of additives, the drop resistance of the pellet samples containing JBC was restored to more than $98 \%$. Furthermore, for the sample with a JB particle size of 80 mesh, the density was $965 \mathrm{~kg} / \mathrm{m}^{3}$, which slightly differed from the recommended standard of the Ministry of Agriculture of China (NY/T 1878-2010), while that of the 30-mesh samples was exactly $1000 \mathrm{~kg} / \mathrm{m}^{3}$. The pellet density of the optimized formula parameter samples decreased by $16.16 \%$ and $10.28 \%$, respectively, compared to the sample prepared from pure JB. However, in terms of fuel performance, the energy density of the optimized formula parameter samples increased by $53.64 \%$ and $53.47 \%$, respectively, compared to the pure JB samples. The overall fuel quality of the samples thus improved significantly, indicating the effectiveness of the biomass carbon and additive applications.

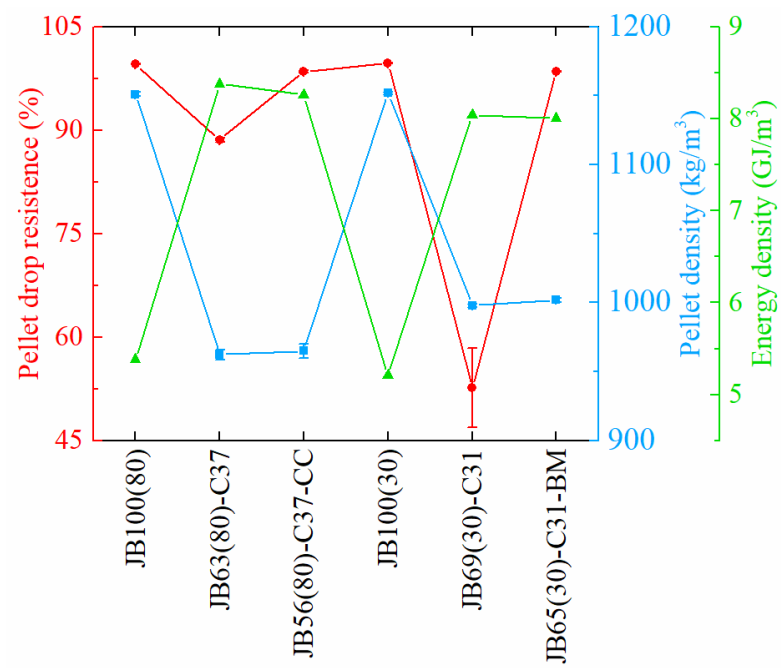

Figure 9. Test results on the drop resistances of the pellets. The samples are named in the form of JB + number $1+$ (number 2$)+C+$ number 3 + additive type. For example, JB56(80)-C37-CC means that the sample consists of 80 mesh JB with a mass fraction of $56 \mathrm{wt} \%$, and JBC with a mass fraction of $37 \mathrm{wt} \%$, with CC as the additive.

\section{Hydrophobicity Analysis}

Hydrophobicity is an important indicator due to the critical influence of the moisture on the physical stability, energy density, and combustion process of pellet [24]. The hygroscopicity of the prepared pellet should be as low as possible during the storage and transportation processes.

Figure 10 reports the moisture uptake curves of samples with two optimized formula parameters and the corresponding samples. Following approximately $2 \mathrm{~h}$, the moisture uptake of each sample began to change significantly; after about $25 \mathrm{~h}$, the moisture uptake of the samples leveled off and gradually stabilized. The European Granular Council standard [46] indicates that the moisture content of the samples should be less than $10 \mathrm{wt} \%$, which was met by all samples in the test. 


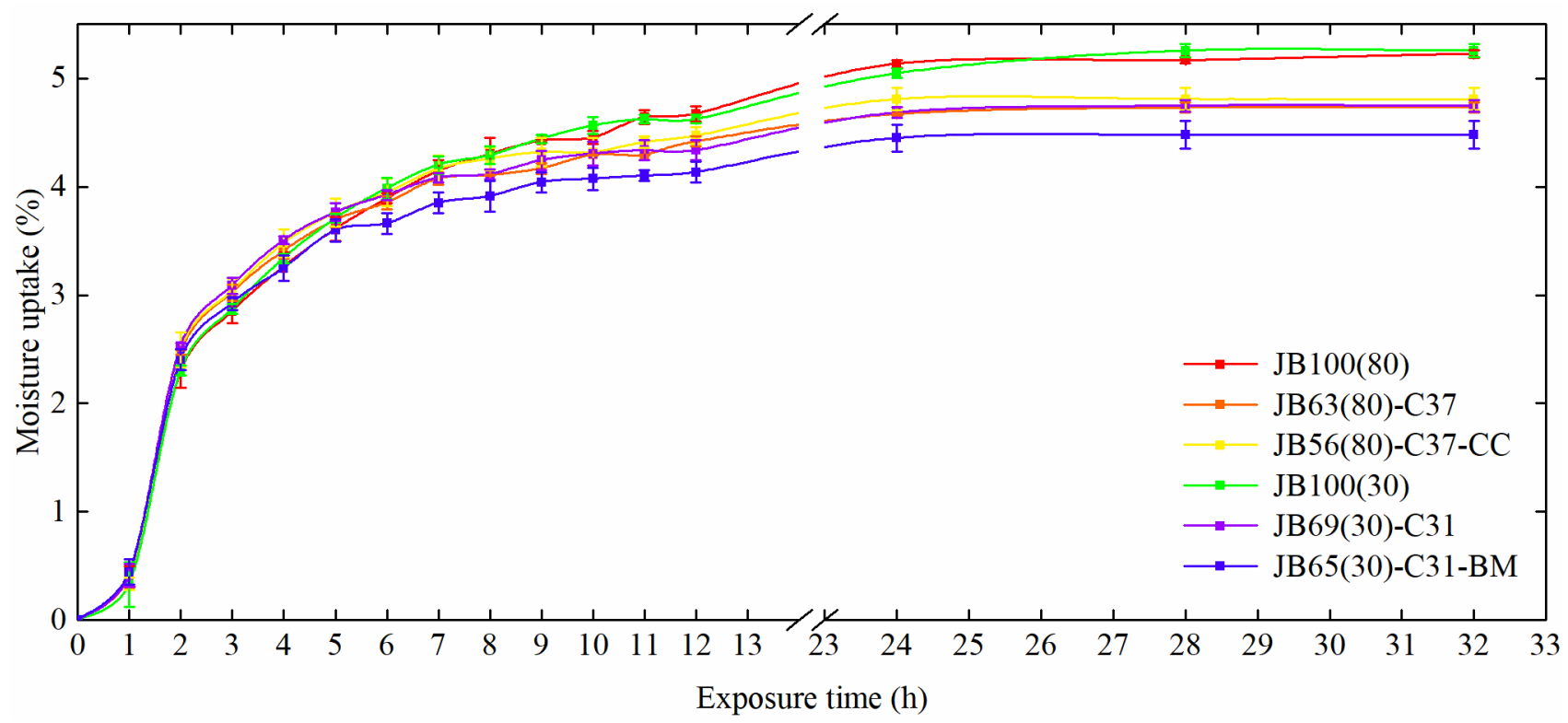

Figure 10. Moisture absorption test results of the different pellet samples. The samples are named in the form of JB + number $1+$ (number 2$)+C+$ number 3 + additive type. For example, JB56(80)C37-CC means that the sample consists of 80 mesh JB with a mass fraction of $56 \mathrm{wt} \%$, and JBC with a mass fraction of $37 \mathrm{wt} \%$, with $\mathrm{CC}$ as the additive.

The maximum moisture uptake values of JB100 (80) and JB100 (30), which were densified from pure JB particles of varying meshes, were highly similar, at $5.23 \pm 0.03 \mathrm{wt} \%$ and $5.25 \pm 0.06 \mathrm{wt} \%$, respectively. When $37 \mathrm{wt} \%$ and $31 \mathrm{wt} \%$ JBC were added, the maximum moisture uptake of JB63(80)-C37 decreased from $5.23 \pm 0.03 \mathrm{wt} \%$ to $4.37 \pm 0.05 \mathrm{wt} \%$, and that of JB69(30)-C31 from $5.25 \pm 0.06 \mathrm{wt} \%$ to $4.75 \pm 0.05 \mathrm{wt} \%$. When CC $(7 \mathrm{wt} \%)$ and BM $(4 \mathrm{wt} \%)$ were added, the maximum moisture uptake of JB56(80)-C37-CC increased from $4.75 \pm 0.05 \mathrm{wt} \%$ to $4.81 \pm 0.10 \mathrm{wt} \%$, whereas the maximum moisture uptake of JB65(30)C37-BM decreased from $4.75 \pm 0.05 \mathrm{wt} \%$ to $4.48 \pm 0.13 \mathrm{wt} \%$.

As described in Section 3.2.2 (Variance Analysis), the added JBC may have wrapped the JB particles, thus hindering the flow of water and the formation of solid bridges. Moreover, the JBC particles are more hydrophobic compared to JB particles; therefore, the added JBC particle may block the water from entering the pellet. This consequently increased the hydrophobicity of the sample. The role of CC was to partially replace the JBC particles on the sample surface, and the CC properties were similar to those of the JB particles, thus slightly increasing the water absorption. The BM also partially replaced the JBC particles on the sample surface. However, its main components were calcium carbonate and calcium phosphate, which are insoluble or slightly soluble in water, further increasing the hydrophobicity of the sample. Although the BM blocked the flow of water, it was difficult to form a solid bridge between the particles [47]. However, due to the filling effects of the BM particles into the void space, it helped to promote the contact of different particles, and further improved the formation of inter-particle bonds in the contact area, thus enhancing the binding [48].

\section{FT-IR Analysis}

The composition of functional groups plays an important role in pellet hydrophobicity. Figure 11 presents the FT-IR spectra of two optimized formula parameters with the corresponding samples. The peaks at $2921-2918 \mathrm{~cm}^{-1}$ are linked to the stretching vibration of aliphatic C-H; the peaks at $1435-1425 \mathrm{~cm}^{-1}$ are characteristic absorption peaks of the $\mathrm{C}=\mathrm{C}$ in benzene ring; the peaks at $1382-1375 \mathrm{~cm}^{-1}$ correspond to the bending vibration of aliphatic $\mathrm{C}-\mathrm{H}$, and the peaks at $1055-1034 \mathrm{~cm}^{-1}$ correspond to the $\mathrm{C}-\mathrm{O}$ bond stretching 
vibrations [49]. These are all hydrophobic functional groups, which could reduce the moisture absorption rate of the pellet during storage and transportation.

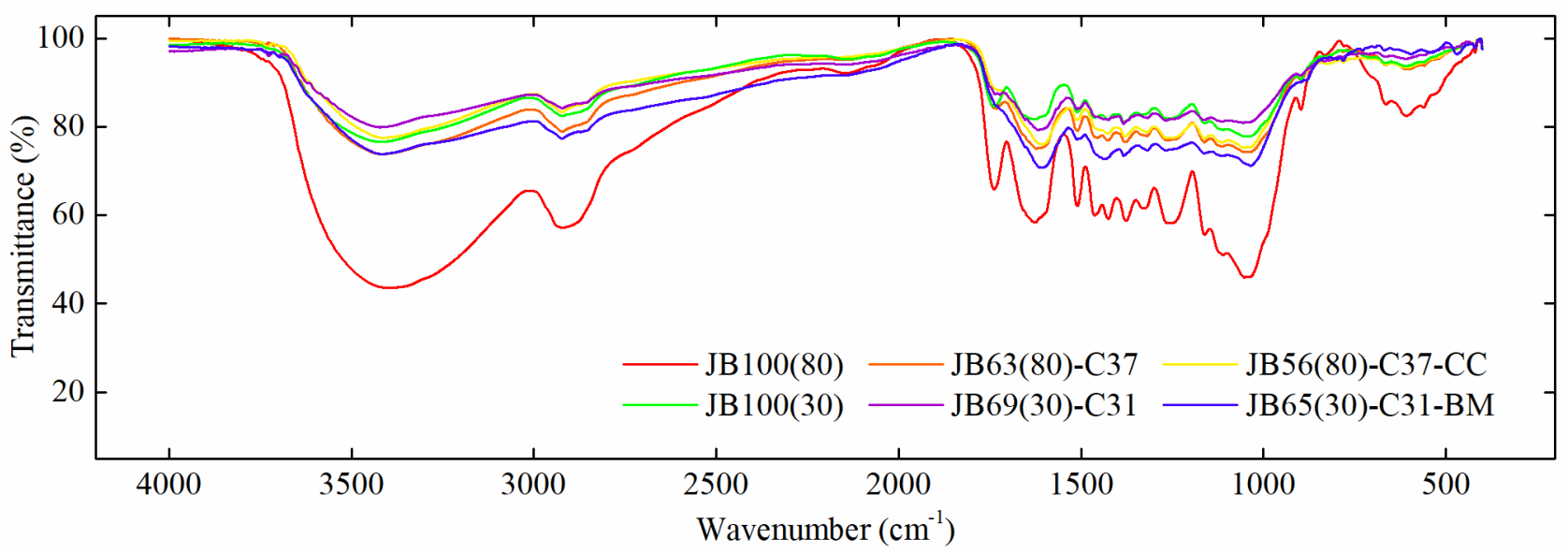

Figure 11. FT-IR spectra of the pellet samples. The samples are named in the form of JB + number $1+$ (number 2) $+\mathrm{C}+$ number 3 + additive type. For example, JB56(80)-C37-CC means that the sample consists of 80 mesh JB with a mass fraction of $56 \mathrm{wt} \%$, and JBC with a mass fraction of $37 \mathrm{wt} \%$, with $\mathrm{CC}$ as the additive.

Thermogravimetric Analysis

In order to study the effects of carbon content and additives on the combustion characteristics of pellets, a thermogravimetric analysis was performed on the pellets before and after optimization. Figure 12 demonstrates the TG and DTG curves of the two samples with optimized formula parameters and their related samples, where JB56(80)-C37-CC corresponds to JB100(80) and JB63(80)-C37, and JB65(30)-C31-BM corresponds to JB100(30) and JB69(30)-C31.

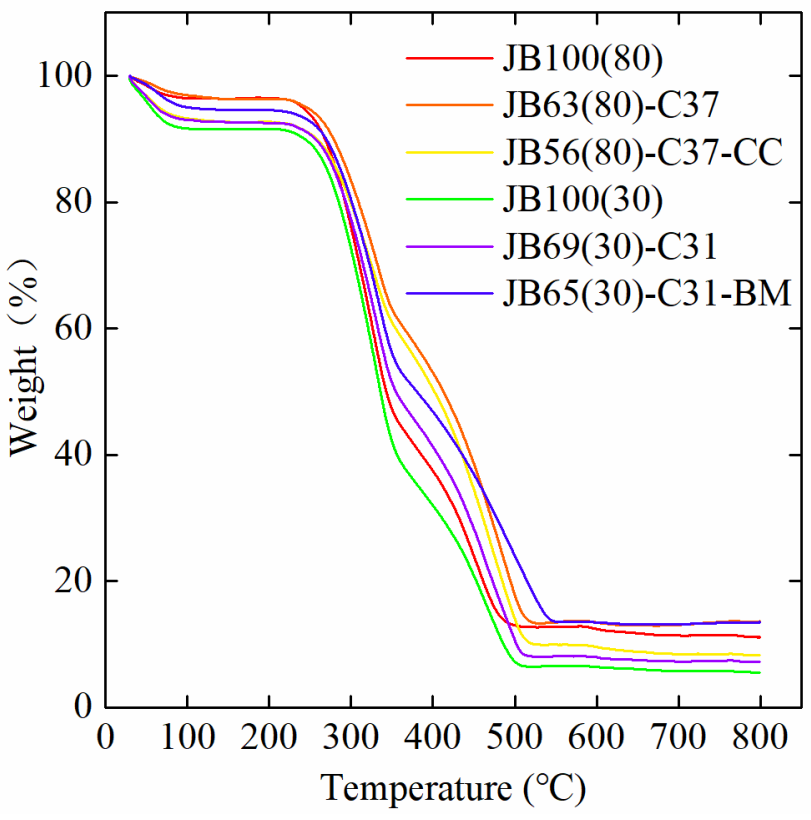

(a)

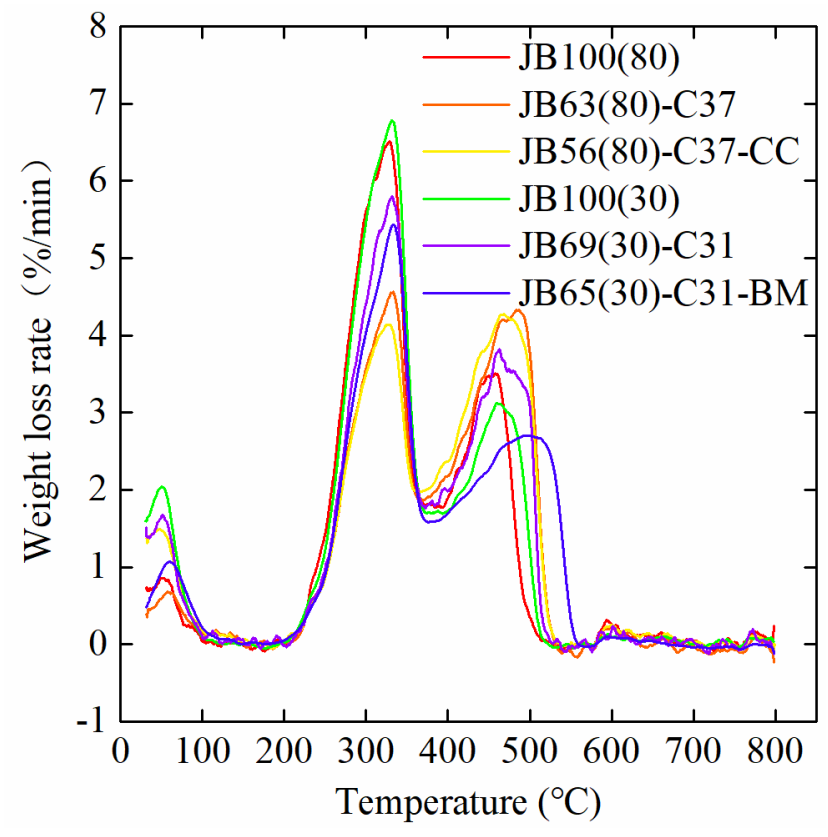

(b)

Figure 12. Thermogravimetric analysis of the pellet samples: (a) TG curve; (b) DTG curve. The samples are named in the form of JB + number $1+($ number 2$)+C+$ number $3+$ additive type. For example, JB56(80)-C37-CC means that the sample consists of 80 mesh JB with a mass fraction of $56 \mathrm{wt} \%$, and JBC with a mass fraction of $37 \mathrm{wt} \%$, with CC as the additive. 
The curves of six pellets were quite similar, indicating that the addition of the JBC and additives did not significantly affect the overall combustion process of pellets (Figure 12a). Notably, the BM significantly increased the residual content following combustion, and the difference between JB100(30) and JB65(30)-C31-BM reached $8.01 \mathrm{wt} \%$, which was more likely to cause slagging in the furnace.

Figure $12 \mathrm{~b}$ depicts the DTG curves of the six pellets. Combining the data in both TG and DTG curves, the ignition temperature, burnout temperature, and combustion time were calculated. Although the ignition temperature of the JBC was approximately $100{ }^{\circ} \mathrm{C}$ higher than that of the JB, its impact on the ignition temperature after blending and densifying with the JB was limited compared with JB100(80) and JB63(80)-C37, as well as JB100(30) and JB69(30)-C31, which increased by $3.9^{\circ} \mathrm{C}$ and $5.9^{\circ} \mathrm{C}$, respectively. Furthermore, the combustion temperature, compared with JB100(80) and JB63(80)-C37, as well as JB100(30) and JB69(30)-C31, increased by $29.4^{\circ} \mathrm{C}$ and $8.1^{\circ} \mathrm{C}$, and the combustion time increased by $11.41 \%$ and $2.35 \%$, respectively. This indicates the improvement of the pellet combustion performance via the JBC blending, releasing more energy. The adoption of the CC reduced the combustion temperature by $1.1{ }^{\circ} \mathrm{C}$ and increased the time by $0.86 \%$ compared JB63(80)C37 between JB56(80)-C37-CC, which had no effect on the combustion characteristics of the pellet. Furthermore, when BM was used as an additive, the combustion temperature and combustion time increased by $32.7^{\circ} \mathrm{C}$ and 14.11\% compared JB69(30)-C31 between JB65(30)-C31-BP. This may result in combustion residue with the bone meal as an additive for the case of insufficient combustion.

\subsection{Cost Evaluation}

The two optimized pellet formulations obtained in this study greatly improved the combustion performance of the biomass densified pellet while simultaneously ensuring its storage and transportation requirements. The applicability of the fuel to actual industrial production was dependent on its cost-effectiveness. However, due to the lack of necessary industrial data, it was not possible to obtain the actual production costs of the biomassdensified pellets used in this study. In order to estimate the application value of pellets, the cost-effectiveness of the pellets for laboratory preparation was calculated.

The raw biomass is typically densified into pellets following three processes: raw material collection, raw material pre-treatment, and pellet production by densification. Hence, the costs were divided into raw material treatment costs and pellet densification costs. For the processing cost of raw materials, the purchase data were based on the actual purchase price of the biomass raw materials, namely, the retail market price. The process parameters and production equipment were the same for all raw material pre-treatment processes. However, the yield of the final usable raw material particles differed across biomass types following sufficient grinding. Thus, the relative content of different particle sizes was different (Figure 1). This resulted in different processing costs for different raw materials. The same process parameters and production equipment were used for the preparation of pellets in the pellet densification process. However, the percentage of different raw materials differed among the different formula parameters. Thus, the costs of the raw materials and pre-treatment were distinct. Moreover, the energy density of the densified pellet differed across formula parameters, indicating the variation in the value of different densified pellets.

The cost effectiveness (relative unit cost) between different types of biomass-densified pellets was investigated. To facilitate the analysis, the raw biomass material processing cost was calculated based on the cost of JB particles with a size of 30 mesh $(\mathrm{JB}(30))$ at the base value of 1.00, while the cost of biomass-densified pellet was calculated using JB100(30) as the base (set to 1.00). The calculation formulas are listed as follows:

$$
\begin{gathered}
R M C o_{\text {Rmt }}=\frac{P P}{P S} P Y(\text { Yuan } / g), \\
R U C o_{R m t}=R M C o_{R m t} / B C o_{R m t},
\end{gathered}
$$




$$
\begin{gathered}
R U C o_{P c}=\sum\left(R U C o_{R m t} \times R M C t\right), \\
R U E D_{P f}=E D_{P f} / B E D, \\
R U E C o_{P f}=R U C o_{P c} \times R U E D_{P f} .
\end{gathered}
$$

In Formulas (1)-(5), $R M C o_{R m t}$ represents the raw material treatment cost; $P P$ represents the raw material market purchase; $P S$ represents the raw material purchasing specifications; $P Y$ represents the raw material process yield; $R U C o_{R m t}$ represents the relative unit cost of the raw material treatment; $B C o_{R m t}$ represents the baseline cost of the raw material treatment; $R U C o_{P C}$ represents the relative unit cost of the pellet densifying process; $R M C t$ represents the raw material content; $R U E D_{P f}$ represents the relative unit energy density of the pellet; $E D_{P f}$ represents the energy density of the pellet; $B E D$ represents the baseline energy density; and $R U E C o_{P f}$ represents the relative unit energy cost of the pellet.

Table 4 reports the relative unit cost of the raw material processing. Despite the low price when using the JB as the main raw material, its relative unit cost was the highest among raw materials as it was more difficult to crush in the pre-treatment stage and required a small particle size. In contrast, taking the JBC as the secondary raw material and $\mathrm{CC}$ and $\mathrm{BM}$ as additives resulted in lower relative unit costs due to the ease of crushing and the required high particle size.

Table 4. Relative unit costs of raw material processing.

\begin{tabular}{cccccc}
\hline $\begin{array}{c}\text { Raw } \\
\text { Materials }\end{array}$ & $\begin{array}{c}\text { Purchase } \\
\text { Price } \\
\text { (yuan) }\end{array}$ & $\begin{array}{c}\text { Purchase } \\
\text { Specifications } \\
\text { (g) }\end{array}$ & $\begin{array}{c}\text { Unit } \\
\text { Price } \\
\text { (Yuan/g) }\end{array}$ & $\begin{array}{c}\text { Relative } \\
\text { Content } \\
\text { (\%) }\end{array}$ & $\begin{array}{c}\text { Raw } \\
\text { Materials } \\
\text { Relative } \\
\text { Unit Cost }\end{array}$ \\
\hline JB(30) ${ }^{\text {a }}$ & 3.00 & 500 & 0.006 & 24.59 & 1.000 \\
JB(80) & 3.00 & 500 & 0.006 & 19.82 & 1.241 \\
JBC & 32.04 & 2500 & 0.013 & 98.69 & 0.532 \\
CC & 11.39 & 2800 & 0.004 & 79.69 & 0.209 \\
BM & 10.32 & 1000 & 0.010 & 98.90 & 0.428 \\
\hline
\end{tabular}

a JB(30): 30 mesh pruned jujube tree branches; JB(80): 80 mesh pruned jujube tree branches; JBC: The charcoal of the pruned jujube tree branches; CC: Coco coir; BM: Bone meal.

Table 5 details the relative cost per unit energy of different pellets. The addition of the JBC and additives reduced the cost of the pellet formation, while increasing the energy density of the fuel. The relative cost per unit energy of the pellet, with the 80 mesh JB particles $(\mathrm{JB}(80))$ as the primary raw material, was reduced by $52.50 \%$ with the addition of the JBC and CC; the equivalent reduction with 30 mesh JB particles $(\mathrm{JB}(30))$ as the principle

\begin{tabular}{|c|c|c|c|c|c|c|c|c|}
\hline \multirow{2}{*}{ Sample } & \multicolumn{5}{|c|}{ Content } & \multirow{2}{*}{$\begin{array}{c}\text { Relative } \\
\text { Unit } \\
\text { Cost }\end{array}$} & \multirow{2}{*}{$\begin{array}{c}\text { Relative } \\
\text { Unit } \\
\text { Energy } \\
\text { Density }\end{array}$} & \multirow{2}{*}{$\begin{array}{c}\text { Relative } \\
\text { Cost } \\
\text { per } \\
\text { Unit Energy }\end{array}$} \\
\hline & $\mathrm{JB}(30)$ & $\mathrm{JB}(80)$ & $\mathrm{JBC}$ & $\mathrm{CC}$ & BP & & & \\
\hline $\mathrm{JB} 100(80)^{\mathrm{a}}$ & 0.00 & 1.00 & 0.00 & 0.00 & 0.00 & 1.24 & 1.03 & 1.20 \\
\hline JB63(80)-C37 & 0.00 & 0.63 & 0.37 & 0.00 & 0.00 & 0.98 & 1.61 & 0.61 \\
\hline JB56(80)-C37-CC & 0.00 & 0.56 & 0.37 & 0.07 & 0.00 & 0.91 & 1.58 & 0.57 \\
\hline JB100(30) & 1.00 & 0.00 & 0.00 & 0.00 & 0.00 & 1.00 & 1.00 & 1.00 \\
\hline JB69(30)-C31 & 0.69 & 0.00 & 0.31 & 0.00 & 0.00 & 0.85 & 1.54 & 0.55 \\
\hline JB65(30)-C31-BM & 0.65 & 0.00 & 0.31 & 0.00 & 0.04 & 0.83 & 1.53 & 0.54 \\
\hline
\end{tabular}
raw material and JBC and $\mathrm{BM}$ as the additives was $46.00 \%$.

Table 5. Relative cost per unit energy of different pellets.

${ }^{a}$ The samples are named in the form of JB + number $1+($ number 2$)+C+$ number $3+$ additive type. For example, JB56(80)-C37-CC means that the sample consists of 80 mesh JB with a mass fraction of $56 \mathrm{wt} \%$, and JBC with a mass fraction of $37 \mathrm{wt} \%$, with $\mathrm{CC}$ as the additive. 
The results reveal the improved performance of the formulated pellets compared to the raw biomass densified pellets in terms of the storage and transportation characteristics and combustion heat, as well as the lower production costs.

However, we would like to mention that the cost estimation presented here is based on the data from this bench-scale study. For further industrialization, more rigorous analyses using data from a large quantity of practical cases should be carried out.

\section{Conclusions}

Biomass-based pellet is an important contributor to the development of alternative fuels, and plays an indispensable role in the promotion of renewable energy. In this study, the formulation of jujube tree (JB)-based pellet using pruned branches was optimized to improve the overall quality. The main conclusions are as follows:

(1) The optimized formulation of JB, JBC, CC or BM in proportion can effectively improve the combustion performance and simultaneously provide the storage and transportation performance.

(2) Cost estimation showed that the two optimized formulations have significant advantages in terms of relative cost per unit energy compared to pellets made from JB alone; therefore, they have potential for commercial applications.

(3) The results revealed that, in the co-densified pellet, the primary raw materials mainly contributed to forming the pellet framework, the secondary raw materials mainly contributed to improving the fuel characteristics, and the additives mainly contributed to enhancing the storage and transportation performance. All these components were found to be critical for complementarily forming the high-quality pellet.

The limitations of this study are: (1) Only the formula parameters were optimized, but the effect of process parameters on pellet quality was not studied; (2) Due to the lack of relevant data, it was impossible to accurately calculate the real cost of pellets. Therefore, it is recommended that future research considers the following two aspects: (1) Considering the influence of process parameters such as pressure, temperature and mold size on pellet quality, in order to further optimize the formula parameters and process parameters; (2) The life cycle assessment method is adopted to analyze the optimization results in order to provide more effective data support for the industrial production of pellet.

Author Contributions: Conceptualization, K.K.; methodology, K.K., Y.L. and W.W.; software, Y.L.; validation, W.W. and Y.L.; formal analysis, K.K. and W.W.; investigation, Y.L.; resources, Y.L.; data curation, Y.L.; writing-original draft preparation, Y.L.; writing-review and editing, K.K. and W.W.; visualization, Y.L.; supervision, K.K. All authors have read and agreed to the published version of the manuscript.

Funding: This research was funded by Natural Science Special Project of Shaanxi Education Department (20JK0499) and Natural Science Basic Research Program of Shaanxi (2020JQ-243).

Data Availability Statement: The is available upon reasonable request from the corresponding author.

Acknowledgments: We thank Longtao Mu and Xiuqing Wang for provide valuable suggestions on this research, and thank Wei Xia, Yan Zhang, Jie Ma and Jingyu Zhang for their help in the tests.

Conflicts of Interest: The authors declare no conflict of interest.

\section{References}

1. Martins, F.; Felgueiras, C.; Smitkova, M.; Caetano, N. Analysis of Fossil Fuel Energy Consumption and Environmental Impacts in European Countries. Energies 2019, 12, 964. [CrossRef]

2. Rehman, A.; Rauf, A.; Ahmad, M.; Chandio, A.A.; Deyuan, Z. The effect of carbon dioxide emission and the consumption of electrical energy, fossil fuel energy, and renewable energy, on economic performance: Evidence from Pakistan. Environ. Sci. Pollut. Res. 2019, 26, 21760-21773. [CrossRef] [PubMed]

3. D'Adamo, I.; Morone, P.; Huisingh, D. Bioenergy: A Sustainable Shift. Energies 2021, 14, 5661. [CrossRef]

4. Xia, T.; Ji, Q.; Zhang, D.; Han, J. Asymmetric and extreme influence of energy price changes on renewable energy stock performance. J. Clean. Prod. 2019, 241, 118338. [CrossRef] 
5. Civitarese, V.; Acampora, A.; Sperandio, G.; Assirelli, A.; Picchio, R. Production of Wood Pellets from Poplar Trees Managed as Coppices with Different Harvesting Cycles. Energies 2019, 12, 2973. [CrossRef]

6. Danish; Wang, Z. Does biomass energy consumption help to control environmental pollution? Evidence from BRICS countries. Sci. Total Environ. 2019, 670, 1075-1083. [CrossRef] [PubMed]

7. Monarca, D.; Cecchini, M.; Colantoni, A. Plant for the production of chips and pellet: Technical and economic aspects of a case study in central Italy. In Proceedings of the International Conference on Computational Science and Its Applications, Santander, Spain, 20-23 June 2011; pp. 296-306.

8. Tursi, A. A review on biomass: Importance, chemistry, classification, and conversion. Biofuel Res. J. 2019, 6, 962-979. [CrossRef]

9. Picchi, G.; Lombardini, C.; Pari, L.; Spinelli, R. Physical and chemical characteristics of renewable fuel obtained from pruning residues. J. Clean. Prod. 2018, 171, 457-463. [CrossRef]

10. Carter, E.; Shan, M.; Zhong, Y.; Ding, W.; Zhang, Y.; Baumgartner, J.; Yang, X. Development of renewable, densified biomass for household energy in China. Energy Sustain. Dev. 2018, 46, 42-52. [CrossRef]

11. Sun, X.; Wei, X.; Zhang, J.; Ge, Q.; Liang, Y.; Ju, Y.; Zhang, A.; Ma, T.; Fang, Y. Biomass estimation and physicochemical characterization of winter vine prunings in the Chinese and global grape and wine industries. Waste Manag. 2020, 104, 119-129. [CrossRef] [PubMed]

12. Alves, C.A.; Vicente, E.D.; Evtyugina, M.; Vicente, A.; Pio, C.; Amado, M.F.; Mahía, P.L. Gaseous and speciated particulate emissions from the open burning of wastes from tree pruning. Atmos. Res. 2019, 226, 110-121. [CrossRef]

13. Nematian, M.; Keske, C.; Ng'Ombe, J.N. A techno-economic analysis of biochar production and the bioeconomy for orchard biomass. Waste Manag. 2021, 135, 467-477. [CrossRef] [PubMed]

14. Kazimierski, P.; Hercel, P.; Suchocki, T.; Smoliński, J.; Pladzyk, A.; Kardaś, D.; Łuczak, J.; Januszewicz, K. Pyrolysis of Pruning Residues from Various Types of Orchards and Pretreatment for Energetic Use of Biochar. Materials 2021, 14, 2969. [CrossRef] [PubMed]

15. Pantaleo, A.; Villarini, M.; Colantoni, A.; Carlini, M.; Santoro, F.; Hamedani, S.R. Techno-Economic Modeling of Biomass Pellet Routes: Feasibility in Italy. Energies 2020, 13, 1636. [CrossRef]

16. Brand, M.A.; Jacinto, R.C. Apple pruning residues: Potential for burning in boiler systems and pellet production. Renew. Energy 2020, 152, 458-466. [CrossRef]

17. Barbanera, M.; Lascaro, E.; Stanzione, V.; Esposito, A.; Altieri, R.; Bufacchi, M. Characterization of pellets from mixing olive pomace and olive tree pruning. Renew. Energy 2016, 88, 185-191. [CrossRef]

18. Riva, L.; Wang, L.; Ravenni, G.; Bartocci, P.; Buø, T.V.; Skreiberg, Ø.; Fantozzi, F.; Nielsen, H.K. Considerations on factors affecting biochar densification behavior based on a multiparameter model. Energy 2021, 221, 119893. [CrossRef]

19. Kang, K.; Qiu, L.; Sun, G.; Zhu, M.; Yang, X.; Yao, Y.; Sun, R. Codensification technology as a critical strategy for energy recovery from biomass and other resources-A review. Renew. Sustain. Energy Rev. 2019, 116, 109414. [CrossRef]

20. Niu, Y.; Tan, H.; Hui, S. Ash-related issues during biomass combustion: Alkali-induced slagging, silicate melt-induced slagging (ash fusion), agglomeration, corrosion, ash utilization, and related countermeasures. Prog. Energy Combust. Sci. 2016, 52, 1-61. [CrossRef]

21. Zhou, Y.; Zhang, Z.; Zhang, Y.; Wang, Y.; Yu, Y.; Ji, F.; Ahmad, R.; Dong, R. A comprehensive review on densified solid biofuel industry in China. Renew. Sustain. Energy Rev. 2016, 54, 1412-1428. [CrossRef]

22. Kang, K.; Qiu, L.; Zhu, M.; Sun, G.; Wang, Y.; Sun, R. Codensification of Agroforestry Residue with Bio-Oil for Improved Fuel Pellets. Energy Fuels 2018, 32, 598-606. [CrossRef]

23. Kang, K.; Zhu, M.; Sun, G.; Qiu, L.; Guo, X.; Meda, V.; Sun, R. Codensification of Eucommia ulmoides Oliver stem with pyrolysis oil and char for solid biofuel: An optimization and characterization study. Appl. Energy 2018, 223, 347-357. [CrossRef]

24. Whittaker, C.; Shield, I. Factors affecting wood, energy grass and straw pellet durability-A review. Renew. Sustain. Energy Rev. 2017, 71, 1-11. [CrossRef]

25. Guan, Y.; Tai, L.; Cheng, Z.; Chen, G.; Yan, B.; Hou, L. Biomass molded fuel in China: Current status, policies and suggestions. Sci. Total Environ. 2020, 724, 138345. [CrossRef]

26. Zhang, Y.; Zhang, Z.; Zhou, Y.; Dong, R. The Influences of Various Testing Conditions on the Evaluation of Household Biomass Pellet Fuel Combustion. Energies 2018, 11, 1131. [CrossRef]

27. Oguntunde, P.E.; Adejumo, O.A.; Odetunmibi, O.A.; Okagbue, H.I.; Adejumo, A.O. Data analysis on physical and mechanical properties of cassava pellets. Data Brief 2018, 16, 286-302. [CrossRef] [PubMed]

28. Gao, W.; Tabil, L.G.; Liu, Q.; Zhao, R.; Zhang, M. Experimental Study on the Effect of Solid-State Fermentation on Pellet Density and Strength of Corn Stover. J. Biobased Mater. Bioenergy 2019, 13, 840-847. [CrossRef]

29. Aller, D.; Bakshi, S.; Laird, D.A. Modified method for proximate analysis of biochars. J. Anal. Appl. Pyrolysis 2017, 124, 335-342. [CrossRef]

30. Zaini, I.N.; Novianti, S.; Nurdiawati, A.; Irhamna, A.R.; Aziz, M.; Yoshikawa, K. Investigation of the physical characteristics of washed hydrochar pellets made from empty fruit bunch. Fuel Process. Technol. 2017, 160, 109-120. [CrossRef]

31. Hu, Q.; Shao, J.; Yang, H.; Yao, D.; Wang, X.; Chen, H. Effects of binders on the properties of bio-char pellets. Appl. Energy 2015, 157, 508-516. [CrossRef]

32. Pradhan, P.; Arora, A.; Mahajani, S.M. Pilot scale evaluation of fuel pellets production from garden waste biomass. Energy Sustain. Dev. 2018, 43, 1-14. [CrossRef] 
33. Kaliyan, N.; Morey, R.V. Factors affecting strength and durability of densified biomass products. Biomass Bioenergy 2009, 33, 337-359. [CrossRef]

34. Shah, M.A.; Khan, M.N.S.; Kumar, V. Biomass residue characterization for their potential application as biofuels. J. Therm. Anal. Calorim. 2018, 134, 2137-2145. [CrossRef]

35. Zheng, Y.; Tao, L.; Yang, X.; Huang, Y.; Liu, C.; Zheng, Z. Comparative study on pyrolysis and catalytic pyrolysis upgrading of biomass model compounds: Thermochemical behaviors, kinetics, and aromatic hydrocarbon formation. J. Energy Inst. 2019, 92, 1348-1363. [CrossRef]

36. Fan, M.; Li, C.; Sun, Y.; Zhang, L.; Zhang, S.; Hu, X. In Situ characterization of functional groups of biochar in pyrolysis of cellulose. Sci. Total Environ. 2021, 799, 149354. [CrossRef] [PubMed]

37. Apaydın-Varol, E.; Pütün, A.E. Preparation and characterization of pyrolytic chars from different biomass samples. J. Anal. Appl. Pyrolysis 2012, 98, 29-36. [CrossRef]

38. El-Hendawy, A.-N.A. Variation in the FTIR spectra of a biomass under impregnation, carbonization and oxidation conditions. $J$. Anal. Appl. Pyrolysis 2006, 75, 159-166. [CrossRef]

39. Zçimen, D.; Ersoy-Meriçboyu, A. Characterization of biochar and bio-oil samples obtained from carbonization of various biomass materials. Renew. Energy 2010, 35, 1319-1324. [CrossRef]

40. Cao, J.; Xiao, G.; Xu, X.; Shen, D.; Jin, B. Study on carbonization of lignin by TG-FTIR and high-temperature carbonization reactor. Fuel Process. Technol. 2013, 106, 41-47. [CrossRef]

41. El-Sayed, S.A.; Ismail, M.A.; Mostafa, M.E. Thermal decomposition and combustion characteristics of biomass materials using TG/DTG at different high heating rates and sizes in the air. Environ. Prog. Sustain. Energy 2019, 38, 13124. [CrossRef]

42. Kok, M.V.; Ozgur, E. Characterization of lignocellulose biomass and model compounds by thermogravimetry. Energy Sources Part A Recover. Util. Environ. Eff. 2017, 39, 134-139. [CrossRef]

43. Kong, L.; Xiong, Y.; Liu, T.; Tu, Y.; Tian, S.; Sun, L.; Chen, T. Effect of fiber natures on the formation of "solid bridge" for preparing wood sawdust derived biomass pellet fuel. Fuel Process. Technol. 2016, 144, 79-84. [CrossRef]

44. Chen, W.-H.; Peng, J.; Bi, X.T. A state-of-the-art review of biomass torrefaction, densification and applications. Renew. Sustain. Energy Rev. 2015, 44, 847-866. [CrossRef]

45. Peng, J.H.; Bi, H.T.; Lim, C.J.; Sokhansanj, S. Study on Density, Hardness, and Moisture Uptake of Torrefied Wood Pellets. Energy Fuels 2013, 27, 967-974. [CrossRef]

46. Duca, D.; Riva, G.; Pedretti, E.F.; Toscano, G. Wood pellet quality with respect to EN 14961-2 standard and certifications. Fuel 2014, 135, 9-14. [CrossRef]

47. Rumpf, H. The strength of granules and agglomerates. In Agglomeration, Proceedings of the First International Symposium on Agglomeration, Philadelphia, PA, USA, 12-14 April 1961; John Wiley \& Sons: New York, NY, USA, 1962; pp. $379-418$.

48. Grover, P.; Mishra, S. Biomass Briquetting: Technology and Practices; Food and Agriculture Organization of the United Nations: Bangkok, Thailand, 1996; Volume 46.

49. Chen, Y.; Liu, B.; Yang, H.; Yang, Q.; Chen, H. Evolution of functional groups and pore structure during cotton and corn stalks torrefaction and its correlation with hydrophobicity. Fuel 2014, 137, 41-49. [CrossRef] 